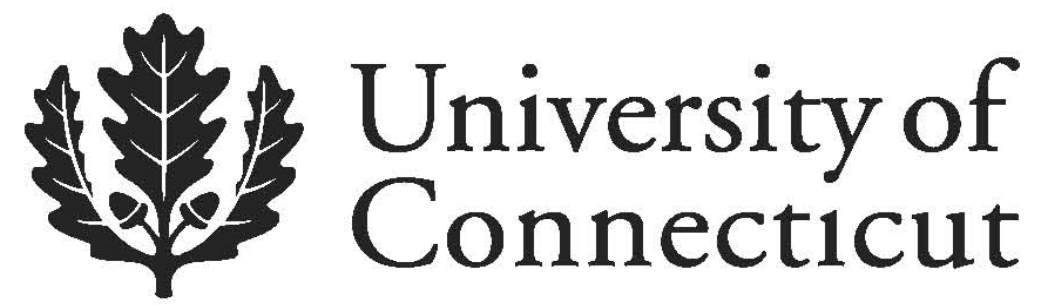

Economics Alumni Working Paper Series

Economic Reforms, Capacity Utilization, and Productivity Growth in Indian Manufacturing

Arnab K. Deb

International Management Institute

Working Paper 2013-05

June 2013

365 Fairfield Way, Unit 1063

Storrs, CT 06269-1063

Phone: (860) 486-3022

Fax: (860) 486-4463

http://www.econ.uconn.edu/

This working paper is indexed on RePEc, http://repec.org 


\begin{abstract}
In this study, we attempt to identify the channels through which economic reforms enhanced the productivity growth in total manufacturing sector in India. Because one possible channel is better utilization of plant capacity, we estimate capacity utilization rate in Indian manufacturing. Empirical estimates show that the annual average capacity utilization rate in Indian manufacturing was lower over the post-reform years. However, after the reforms capacity utilization rate grew faster at the all India level as well as for most of the major industrial states. Subsequent regression analysis confirms that there was evidence of a favorable impact of economic reforms on productivity growth in total manufacturing, beyond the positive impact of improved capacity utilization.
\end{abstract}

JEL Classification: C14, C61, D24, L60, O53

Keywords: Economic Reform, Total Factor Productivity, Data Envelopment Analysis, Malmquist Index, Gross Capacity Utilization, Net Capacity Utilization. 


\title{
Economic Reforms, Capacity Utilization, and Productivity Growth in Indian Manufacturing
}

\author{
Arnab K. Deb \\ arnab.deb@imi.edu \\ International Management Institute, New Delhi, India
}

\section{Introduction}

The most important rationale of the economic reform process of 1991 was to make a deliberate shift toward an open economy to improve efficiency and productivity. Introduced gradually, these reforms led to a significant reduction in the number of industries reserved for the public sector. Privatization of a large segment of the economy, elimination of licensing requirements for industrial investment in most industries and amendment of the Monopolies and Restrictive Trade Practice (MRTP) Act to remove barriers to entry and capacity expansion by large industrial houses prompted a more flexible and liberalized industrial structure. To supplement these new industrial policies, drastic depreciation of the Indian Rupee, removal of licensing and other physical controls on importation of capital and consumer goods, widening the scope of foreign direct investment, and lowering of tariffs were the major components of the trade liberalization process.

The impact of economic reforms on total factor productivity of the Indian organized manufacturing sector has been a subject of intense debate among empirical analysts over the last two decades. A large body of literature including (but not limited to) Trivedi, Prakash, and Sinate, 2000, Ray, 2002, Aghion, Burgess, Redding, and Zilibotti ,2003, Unel, 2003, Goladar and Kumari, 2003, Trivedi, 2004, Das, 2004, Topalova, 2004, Goldar, 2004, Milner, 2007, Das and Kalita, 2009, and Trivedi, Lakshmanan, Jain, and Gupta,2011 evaluated manufacturing industries in terms of total factor productivity growth and finds 
mixed evidence on the same. In a recent study, using the non-parametric method Data Envelopment Analysis, Deb and Ray, 2013 constructs Malmquist index of total factor productivity and examines how the nature and pace of the growth in manufacturing productivity in different Indian states have differed during the pre-reform and post reform years. Measured rates of growth in total factor productivity over the years 1970-71 through 2007-08 reveal that even though there was variation across states, post-reform years witnessed faster productivity growth in Indian manufacturing. This observed improvement in productivity growth rate can readily be credited to economic reforms. Nevertheless, the important question is what the channels are through which reforms enhanced productivity growth.

Total factor productivity growth measured in by the difference between growth rates of output and aggregate input is based on a production and optimization framework which assumes that all inputs are instantaneously adjustable leading a firm to be in long-run equilibrium. This ignores the important role of short run fixity of certain inputs. In fact, a firm is often in a short-run or temporary equilibrium. Temporary equilibrium occurs when because of high adjustment costs it is not economically meaningful to adjust certain inputs instantly as the output changes due to demand fluctuations. The factors causing demand fluctuations include changes in domestic or foreign demand caused by changes in tastes or by the cyclical variations in the macroeconomic situation. Inaccurate forecasts of the quantity demanded or of changes in demand patterns and creation or expansion of capacities based on such forecasts may result in excess capacities when realized demand falls short of the anticipated levels Srinivasan, 1992. Consequently, underutilization of capacity resulting from a shortfall in demand yields a low level of production and accordingly can slow down the productivity growth in an industry. On the other hand, even in the presence of sufficient demand, the supply factors can also affect capacity utilization and generate excess capacity. These factors include unavailability of inputs such as raw materials, infrastructural bottlenecks such as power shortage and transport bottlenecks, and factors such as closure of units due to labor disputes. 
This paper extends Deb and Ray, 2013 and aims to statistically verify whether the observed improvement in manufacturing productivity took place through better capacity utilization alone or economic reforms enhanced productivity through other channels as well. In order to get a measure of capacity utilization rate we first compute annual physical ${ }^{l}$ capacity output for an average firm from the state level inputoutput data for the period from 1970-71 through 2007-08. We choose to measure physical measure of capacity output primarily because of two reasons. First, since actual output produced is used to compute the capacity output, capacity utilization rate measured from it agrees more with the fluctuations in production associated with the demand for output. Secondly, unlike the economic measure, physical measure of capacity output does not require information on input prices and thus provides an alternative when information on input prices is unavailable or unreliable. Since we do not have information on the interstate variation in input prices, computing economic capacity output could provide inaccurate estimate of capacity utilization rate. Next, on the basis of the resulting estimate of capacity output we measure both gross and net capacity utilization rates (explained below) of the average manufacturing firms in major Indian states and examine how the growth pattern of capacity utilization rate has changed over the years.

This paper unfolds in the following manner. Section 2 provides a review of relevant literature on the relationship between plant capacity utilization and total factor productivity growth. We also discuss those studies which provide evidence on variation in capacity utilization rate in Indian manufacturing. Section 3 briefly describes and differentiates between the concepts of economic and physical capacity output. In section 4 we discuss how we measure gross and net capacity utilization rate. Section 5 presents the nonparametric DEA model introduced by Färe, Grosskopf, and Kokkelenberg, 1989 to compute capacity utilization rates. We discuss the data and empirical application in section 6. We present the measured capacity utilization rate in Indian manufacturing for major Indian states in section 7. The specification of a one-way fixed effect model, and estimation of it by between-effects estimation technique to identify the

\footnotetext{
${ }^{1}$ For a detailed discussion on economic and physical concept of capacity output see section 3 .
} 
channels through which productivity growth in Indian manufacturing accelerated are presented in section 8. Section 9 concludes.

\section{Literature Review}

Several studies have used a variety of cyclical adjustments to take account of variations in the utilizations of capacity of fixed inputs. Jorgenson and Grileches, 1967 adjust for the variation in capital utilization using the relationship between electricity consumption and the horse power rating of electric motors. Denison, 1974, in a number of studies, uses variations in capital's share of income as a measure of capacity utilization. These adjustment procedures have been controversial primarily because they lack any theoretical motivation.

Berndt and Fuss, 1982 and 1986 use the Marshallian framework of a short run production or cost function with a subset of quasi-fixed inputs and provided a basis for accounting for temporary equilibrium effects, such as variation in capacity utilization. Their empirical application to U.S. manufacturing data for the period 1958-59 through 1981 shows that depending on the measures of output, between $18 \%$ and $65 \%$ of measured decline in total factor productivity growth can be attributed to the effects of capacity utilization.

Morrison,1986 focuses on the distinction between short and long run production behavior represented by capacity utilization indexes, and on the adjustment of observed productivity measures for the effects of short run fixity captured by these indexes. She develops a dynamic optimization model based on adjustment costs for quasi-fixed inputs to calculate capacity utilization adjustments for productivity growth measures. The resulting framework was then used to identify empirically the effects of capacity utilization, non-static expectations, adjustment costs and non-constant returns to scale on productivity in the U.S. manufacturing sector. Primary finding from that study is that both capacity utilization and anticipatory behavior had substantial impact on observed productivity measures. 
On the basis of Berndt and Fuss, 1982 and 1986 framework, Hulten,1986 defines the change in economic efficiency as the rate of change of real short run cost and decomposes growth rate of real short-run average cost into two terms: long run changes due to growth of technical efficiency and short run changes in efficiency due to variation in the utilization in capital. Instead of econometric estimation of the parameters of the production function as in Morrison, 1986, the cost-utilization decomposition is carried out along index number line. He also examines the relationship between the 'false' multi-factor productivity residual obtained by erroneously assuming that all factors are fully flexible and the 'true' multi-factor productivity residual. It is shown that the difference between false and true multi-factor productivity residuals is due to capacity utilization effect.

Another strand in the literature took the Federal Reserve's measure of capacity utilization and investigates the macroeconomic implications of a high or low utilization rate. Shapiro, 1989 investigates the dynamic relationship between lagged capacity utilization rates (as measured by the Federal Reserve) and production, between lagged utilization rates and changes in relative prices, and also between utilization and other macroeconomic variables. His findings do not support the hypothesis that high capacity utilization acts as a barrier to further output expansion. On the other hand, using the Federal Reserve's capacity utilization measures for the aggregate U.S. manufacturing sector for 1967-95, Corrado and Mattey, 1997 find noticeably positive correlation between the capacity utilization rates and the acceleration of consumer prices excluding food and energy. The correlation between manufacturing capacity utilization and acceleration of manufactured goods prices is even higher. They find that inflation begins to accelerate particularly when capacity utilization exceeds a threshold level.

In the context of Indian manufacturing, to date there is only one study by Goldar and Kumari, 2003 that examines the role of variation in the capacity utilization in explaining the inter-industry and intertemporal variation in productivity growth rates. They estimate capacity utilization at the national level for 
different industry groups on the basis of electricity consumption ${ }^{2}$ and identify underutilization of industrial capacity as an important cause of productivity slowdowns. Other studies which also provide empirical evidence of inter-temporal variation in manufacturing capacity utilization during the postreform years are Uchikawa, 2001, Azeez, 2005, Gajanan and Malhotra, 2007, and Goldar and Renganathan, 2008). But these studies mainly focus on explaining the variation in capacity utilization changes rather than the effect this variation might have on the variation in total factor productivity growth rates.

\section{Concept of Capacity Output}

Measuring the rate of capacity utilization requires identifying the capacity output. Capacity is a short-run concept, for which firms and industry face short-run constraints, such as the stock of capital or other fixed inputs, existing regulations, the state of technology and other technological constraints (Morrison, 1986). In the relevant literature, capacity output has been defined in two alternative ways; (1) economic concept and (2) physical or engineering concept.

\subsection{Economic Concept}

Due to Cassels, 1937, economic capacity output of the firm is the level of production where the firm's long-run average cost curve reaches a minimum. Because long-run average cost is considered, no input is held fixed. So, the economic measure pertains to capacity utilization of all inputs. For a firm with the typical U-shaped average cost curve, at this capacity level of output, economies of scale have been exhausted but diseconomies have not yet set in Ray, Mukherjee, and $\mathrm{Wu}, 2006$. If the technology exhibits constant returns to scale, the long-run average cost curve is horizontal and does not have a minimum. So the capacity level of output is not defined. Klein, 1960 proposes the output level where the short-run

\footnotetext{
${ }^{2}$ This methodology was applied earlier by Mulega and Weiss, 1996). The ratio of electricity consumption to capital stock is first computed for different years in the period under study. A trend line is fitted to the data, which is then shifted up so that it passes through the point having largest positive residual. The actual ratio of electricity to capital is then compared with the ratio indicated by the trend line (adjusted) to compute capacity utilization.
} 
average cost curve is tangent to the long-run average cost curve as a measure of the capacity output. This is also the approach adopted by Berndt and Morrison, 1981. This helps to determine the economic capacity output level in the short run and yields a measure of the rate of capacity utilization of the fixed input. $^{3}$

\subsection{Physical Concept}

In contrast, under the physical or engineering measure, capacity output is defined as the maximum output that can be produced from a specific bundle of the quasi-fixed inputs even when there is no restriction on the availability of variable inputs (Johansen, 1968). Therefore, the physical limit defines the capacity of one or more quasi-fixed input. Capacity output thus defined is related to the concept of a short-run production function, rather than the more commonly used cost framework.

Theoretically capacity output (physical) can be explained in the following manner. Consider an $m$-output, $n$-input production technology. An input-output combination $(x, y)$ is a feasible production plan if the output bundle $y$ can be produced from the input bundle $x$. The set of all feasible production plans constitute the production possibility set

$T=\{(x, y): y$ can be produced from $x\}$

In the single output case the production function may be defined as

$$
f(x)=\max y:(x, y) \in T
$$

Under the assumptions of free disposability of inputs and output, the maximum producible output by a production unit using input bundle $x_{0}$ is

$$
y_{0}^{*}=f\left(x_{0}\right)=\max y: x \leq x_{0},\left(x_{0}, y\right) \in T
$$

The output oriented technical efficiency of firm producing output $y_{0}$ from input $x_{0}$ is

\footnotetext{
${ }^{3}$ Segerson and Squires, 1990 proposed a measure for economic capacity utilization for a multi-output firm and applied it to the multi-species New England fishing industries to evaluate the potential for capacity expansion under a regulatory programme of license limitation.
} 
$T E\left(x_{0}, y_{0}\right)=\frac{y_{0}}{y_{0}^{*}}=\frac{y_{0}}{f\left(x_{0}\right)}$

Suppose the input vector $x$ of the production unit can be partitioned into a sub-vector of variable inputs $x^{v}$ and sub-vector of quasi-fixed inputs $x^{f}$. Then following Johansen (1968) the capacity output for the quasi-fixed input $x_{0}^{f}$ is

$y_{0}^{* *}=f\left(x^{v}, x_{0}^{f}\right)=\max y:\left(x^{v}, x^{f}, y\right) \in T, x^{f} \leq x_{0}^{f}, x^{v} \geq 0$

Note that (5) implies that $x^{f}$ can be kept partially idle. Also there is no upper limit on $x^{v}$.

\section{Measure of Capacity Utilization Rate}

We measure physical capacity utilization rate in two different ways. First, we measure the capacity utilization rate as the ratio of actual output produced by a firm over maximum potential plant capacity when fixed inputs are given as observed and all other inputs are allowed to vary freely. We denote this capacity utilization rate as gross capacity utilization rate (gcur). Accordingly, the gross capacity utilization rate is measured as $g c u r=\frac{y_{0}}{y_{0}^{* *}}$

where, $y_{0}^{* *}$ is the capacity output and $y_{0}$ is the actual output.

An alternative measure is the net capacity utilization rate ( $n c u r)$. The gross measure of capacity utilization is based on the gap between the actual and the physical capacity output. When technical inefficiency exists, part of this gap can be bridged by merely eliminating such inefficiency. However, this is an improvement in efficiency rather than an increase in the rate of capacity utilization. ${ }^{4}$ The remaining gap between capacity and technically efficient output then gives the net measure of capacity utilization. Therefore, the net capacity utilization rate of a production unit is defined as the ratio of maximum

\footnotetext{
${ }^{4}$ Recently Knox Lovell characterized the gap between actual and technically efficient output as wasted capacity and the gap between technically efficient and capacity output as the idle capacity.
} 
potential output when all inputs are given as observed over maximum potential plant capacity when fixed inputs are given as observed and all other inputs are allowed to vary freely.

The net capacity utilization rate is measured as

$$
\text { ncur }=\frac{y^{*}}{y_{0}^{* *}}=\frac{\left(\frac{y_{0}}{y_{0}^{* *}}\right)}{\left(\frac{y_{0}}{y_{0}^{*}}\right)}
$$

where, $y_{0}^{*}$ is the technically efficient output.

It should be noted that $g$ cur $\leq$ ncur because $y_{0} \leq y_{0}^{* *}$.

Figure 1 illustrates graphically the concepts of different measures of capacity utilization rate described above, for the case of one output-two input. The total product curves in figure 1 show the maximum quantities of output from different quantities of variable inputs $L$ when equipped with two different quantities of the quasi-fixed input ( $K_{0}$ and $K_{1}$ ). For $K$ equal to $K_{0}$ the total output increases with $L$ (up to $\left.L_{0}^{*}\right)$ along the OBG segment of the curve $f\left(L, K_{0}\right)$. Thereafter, an increase in variable input $L$ does not lead to a higher level of output. It remains constant at $Y_{0}^{* *}=f\left(L, K_{0}\right)$.

Thus, the technically efficient output is $Y_{0}^{*}=\min \left\{f\left(L, K_{0}\right) ; Y_{0}^{* *}\right\}$. Hence, $Y_{0}^{* *}$ is the capacity output for the quasi-fixed input level $K_{0}$.

Similarly, for the higher level of the quasi-fixed input, $K_{1}$ the total product curve becomes horizontal at the point $\mathrm{H}$ once $L$ has increased to $L_{1}^{*}$ and $Y_{1}^{*}=\min \left\{f\left(L, K_{1}\right) ; Y_{1}^{* *}\right\}$ where, $Y_{1}^{* *}=f\left(L_{1}^{*}, K_{1}\right)$ is the capacity output level for $K_{1}$. 
Suppose that a firm is producing output $Y_{0}$ from the input bundle $\left(L_{0}, K_{0}\right)$. This is shown by the point A. In that case, its technical efficiency is $\frac{Y_{0}}{Y_{0}^{*}}=\frac{A L_{0}}{B L_{0}}$, whereas the gross measure of capacity utilization rate is $\operatorname{gcur}_{0}=\frac{Y_{0}}{Y_{0}^{* *}}=\frac{A L_{0}}{C L_{0}}$.

The net measure of capacity utilization rate is $n c u r_{0}=\frac{Y_{0}^{*}}{Y_{0}^{* *}}=\frac{B L_{0}}{C L_{0}}$.

Similarly, for output $Y_{1}$ produced from the input bundle $\left(L_{1}, K_{1}\right)$ as shown by point $\mathrm{D}$, technical efficiency is $\frac{Y_{1}}{Y_{1}^{*}}=\frac{D L_{1}}{E L_{1}}$.

The gross measure of capacity utilization rate is $\operatorname{gcur}_{1}=\frac{Y_{1}}{Y_{1}^{* *}}=\frac{D L_{1}}{F L_{1}}$ and the net measure of capacity utilization rate is $n c u r_{1}=\frac{Y_{1}^{*}}{Y_{1}^{* *}}=\frac{E L_{1}}{F L_{1}}$

\section{Non-parametric Methodology to Estimate Capacity Utilization Rate}

This paper adopts the non-parametric method of Data Envelopment Analysis (DEA) introduced by Charnes, Cooper and Rhodes, 1978 (CCR) and further generalized for variable returns to scale technology by Banker, Charnes, and Cooper, 1984 (BCC), in order to measure gross and net capacity utilization rate.

The major advantage of using DEA is that, unlike in the parametric approach, there is no need to specify any explicit functional form for the production function (e.g., Cobb-Douglas or Translog) and mathematical programming techniques can be used to get point-wise estimates of the production function. In fact, DEA allows one to construct the production possibility set from observed input-output bundles on the basis of the following four assumptions: 

a. all observed input-output combinations are feasible;
b. the production possibility set is convex;
c. inputs are freely disposable; and
d. outputs are freely disposable.

Now, consider an industry producing one output $y$ from one input $x$. The input-output bundle $(x, y)$ is considered as feasible if the output $y$ can be produced from the input $x$. Let $\left(x_{j}, y_{j}\right)$ represent the inputoutput bundle of firm $j$; and suppose that input-output data are observed for $n$ firms. Then, based on the above assumptions, the production possibility set showing a variable returns to scale (VRS) technology is $T_{v}=\left\{(x, y): x \geq \sum_{j=1}^{n} \lambda_{j} x_{j} ; y \leq \sum_{j=1}^{n} \lambda_{j} y_{j} ; \sum_{j=1}^{n} \lambda_{j}=1 ; \lambda_{j} \geq 0 ;(j=1,2,3, \ldots . ., n)\right\}$.

Under the constant returns to scale (CRS) assumption, if any $(x, y)$ is feasible, so is the bundle $(k x, k y)$ for any $k>0$. The production possibility set then becomes

$$
T_{c}=\left\{(x, y): x \geq \sum_{j=1}^{n} \lambda_{j} x_{j} ; y \leq \sum_{j=1}^{n} \lambda_{j} y_{j} ; \lambda_{j} \geq 0 ;(j=1,2,3, \ldots ., n)\right\} .
$$

One can measure the output-oriented technical efficiency $T E\left(x_{s}, y_{s}\right)$ of a firm $s_{s}$ by comparing its actual output $y_{s}$ with the maximum producible quantity from its observed input $x_{s}$. Therefore, the outputoriented technical efficiency of firm $s$ is

$T E\left(x_{s}, y_{s}\right)=\left(\frac{1}{\theta_{s}^{*}}\right) ;$ where, $\theta_{s}^{*}=\max \theta:\left(x_{s}, \theta y_{s}\right) \in T$ and $T$ represents the production possibility 
set $^{5}$.

An alternative characterization of technical efficiency in terms of the Shephard Distance Function is $D\left(x_{s}, y_{s}\right)=\min \delta:\left(x_{s}, \frac{1}{\delta} y_{s}\right) \in T$. It can be seen that $\delta=\frac{1}{\theta_{s}^{*}}$.

The standard non-parametric DEA model used to estimate output-oriented technical efficiency of a firm $S$, relative to a CRS frontier is

$$
\theta_{s}^{*}=\operatorname{Max} \theta
$$

$$
\begin{array}{ll}
\text { Subject to } \quad & \sum_{j=1}^{n} \lambda_{j} y_{j} \geq \theta_{s} ; \\
& \sum_{j=1}^{n} \lambda_{j} x_{j} \leq x_{s} ; \\
& \lambda_{j} \geq 0 ;(j=1,2,3, \ldots n) ; \\
\text { and, } \quad & T E_{c}\left(x_{s}, y_{s}\right)=\left(\frac{1}{\theta_{s}^{*}}\right) .
\end{array}
$$

By imposing the additional restriction $\sum_{j=1}^{n} \lambda_{j}=1$ in this DEA model, output-oriented technical efficiency, $T E_{v}\left(x_{s}, y_{s}\right)$, of a firm $s$ with reference to a VRS frontier can be estimated.

Färe et al., 1989 develop a non-parametric (linear programming) framework in which physical capacity, and a measure of the capacity utilization rate can be determined from data on observed inputs and outputs.

\footnotetext{
${ }^{5}$ Farell, 1957 formulated a linear programming model to estimate the output-oriented technical efficiency of a firm with observed input-output bundle with reference to a benchmark technology.
} 
Suppose that $\left.x_{j}=\left(x_{j}^{v}, x_{j}^{f}\right)\right)$ is the observed bundle of variable and quasi-fixed inputs and $y_{j}$ is the output of firm $j(\mathrm{j}=1,2, \ldots, n)$ in the sample. Recall that under the standard assumptions of convexity and free disposability of inputs and outputs, the production possibility set constructed from the data is

$$
\begin{aligned}
& T=\left\{\left(x^{v}, x^{f}, y\right): x^{v} \geq \sum_{j}^{n} \lambda_{j} x_{j}^{v} ; x^{f} \geq \sum_{j}^{n} \lambda_{j} x_{j}^{f} ; y \leq \sum_{j}^{n} \lambda_{j} y_{j} ;\right. \\
& \left.\sum_{j=1}^{n} \lambda_{j}=1 ; \lambda_{j} \geq 0 ;(j=1,2,3, \ldots . ., n)\right\}
\end{aligned}
$$

Following, Banker et al., 1984 for the input-output bundle $\left(x_{0}^{v}, x_{0}^{f}, y_{0}\right)$, we have, $y_{0}^{*}=\varphi^{*} y_{0}$ where,

$$
\varphi^{*}=\operatorname{Max} \varphi
$$

Subject to, $\quad \sum_{j=1}^{n} \lambda_{j} y_{j} \geq \varphi y_{0}$

$$
\begin{aligned}
& \sum_{j=1}^{n} \lambda_{j} x_{j}^{v} \leq x_{0}^{v} ; \sum_{j=1}^{n} \lambda_{j} x_{j}^{f} \leq x_{0}^{f} \\
& \sum_{j=1}^{n} \lambda_{j}=1 ; \lambda_{j} \geq 0 ;(j=1,2,3, \ldots ., n)
\end{aligned}
$$

Further, as shown by Färe et al., 1989,

$y_{0}^{* *}=\varphi^{* *} y_{0}$ where,

$$
\varphi^{* * *}=\operatorname{Max} \varphi
$$

Subject to, $\quad \sum_{j=1}^{n} \lambda_{j} y_{j} \geq \varphi y_{0}$;

$$
\begin{aligned}
& \sum_{j=1}^{n} \lambda_{j} x_{j}^{\nu} \leq x^{\nu} ; \sum_{j=1}^{n} \lambda_{j} x_{j}^{f} \leq x_{0}^{f} \\
& \sum_{j=1}^{n} \lambda_{j}=1 ; \lambda_{j} \geq 0 ;(j=1,2,3, \ldots ., n)
\end{aligned}
$$


Note that because the vector of variable inputs $x$ in the constraint is itself unrestricted, there is effectively no constraint on these inputs.

We measure technically efficient output and capacity output by solving model (12) and (13) respectively, with respect to a production possibility frontier which is constructed by pooling inputoutput data for two adjacent years. Accordingly capacity utilization index measuring rate of change in capacity utilization becomes

$$
\operatorname{cui}\left(x_{t}{ }^{v}, x_{t}^{f}, y_{t} ; x_{t+1}{ }^{v}, x_{t+1}^{f}, y_{t+1}\right)=\frac{\operatorname{cur}_{t+1}}{c u r_{t}}
$$

\section{Data and Empirical Application}

Using the state level input-output data $^{6}$ obtained from ASI, we compute the measure of gross capacity utilization rate (gcur) and the measure of net capacity utilization rate (ncur) for Indian manufacturing for the period 1970-71 through 2007-08. The period from 1970-71 through 1991-92 is treated as the prereform period and the remaining years are considered as the post-reform years.

The input-output data reported in the ASI for individual states are aggregates over all firms in the state covered by the Survey. Even though, the actual input-output quantities of the individual firms are all feasible bundles, the total input-output bundle - the sum of those feasible bundles - is neither observed nor a weighted average of feasible observations. This aggregation poses a serious technical problem and applying DEA to this data violates underlying assumption for constructing production possibility frontier. Assumptions of constant returns to scale along with convexity of the production possibility set would ensure the feasibility of these aggregate input-output bundles. Nevertheless, the assumption - a reference technology showing CRS throughout the production process - is quite restrictive for such an analysis.

\footnotetext{
${ }^{6}$ We construct the input-output variables in the same manner as we did while measuring total factor productivity growth in Indian Manufacturing (see Deb and Ray, 2013 for details).
} 
Therefore, in order to avoid this aggregation problem we use the average input-output bundle ${ }^{7}$ for any state as a feasible combination and as a basis for constructing the non parametric production possibility frontier.

\section{Empirical Estimates of Capacity Utilization Rate and Capacity Utilization Growth}

In Tables 1 and 2 we report the annual averages of these two measures at the All-India as well as at the state level. Also in Tables 3 and 4 we provide state-wise estimates of rates of change in gross and net capacity utilization rate for the pre-reform as well as for the post reform years.

Estimates of rates of change in gross capacity utilization in total manufacturing show that at the all-India level, capacity utilization rate improved by 1.68 per cent per year during the entire sample period. We also observe that during the entire study period, on a year to year average Indian manufacturing utilized $62 \%$ of its capacity at the national level. Over the years 1970-71 through 1991-92 average capacity utilization rates was 65 per cent per year. However, during this period annual capacity utilization rate showed a steady downward trend (see Figure 3) and declined by around 0.6 per cent per year. The yearwise analysis (see Table 5 and Figure 2) reveals that there is continuous decline in capacity utilization rate during the period of 1982-83 to 1990-91. In the year 1982-83 capacity utilization rates reached its peak of 75 per cent. The lowest rate of 46 per cent was attended in 1990-91. One possible explanation for this sharp decline, mainly during the latter part of this period, is increasing labor dispute in Indian states. The average duration of lockouts and strikes increased considerably in the 1980s and consistently remained

\footnotetext{
${ }^{7}$ The average input-output bundle is an equally weighted average of the unobserved input-output bundles of the individual firms from a state, and by convexity assumption each of these bundles is feasible.

Let $(X, Y)$ represent the aggregate input-output bundle for a state. Assuming that there are $n$ individual firms in this state, let $\left(x_{f}, y_{f}\right)$ represent the input-output bundle of firm $f(f=1,2, \ldots \ldots n)$. Hence, $X=\sum_{f=1}^{n} x_{f}$ and $Y=\sum_{f=1}^{n} x_{f}$. We know that the firm-level input-output pairs, although not individually reported are all feasible. Hence by the convexity assumption the average input-output bundle $\left(\frac{1}{n} \sum_{f=1}^{n} x_{f}, \frac{1}{n} \sum_{f=1}^{n} y_{f}\right)$ will always be feasible
} (Ray, 2002, Ray, 2009). 
high relative to that in the previous decades (see Shyam Sundar, 2004) for detailed statistics on labor dispute in this period). Saha and Pan, 1994 characterized this latter part of the 1980s as the period of 'lock-out dominance'. Even though Indian manufacturing started to get access to better access to capital goods during this period the restricted availability of labor input possibly explains the underutilization of capital inputs. Because annual capacity utilization rate reached the lowest in 1990-91, in spite of the fact that it started to grow at the rate of $4.56 \%$ per year, the annual average dropped to 59 per cent over the post-reform period.

From state level estimates of capacity utilization rate we observe that on an average, manufacturing sectors in Chandigarh, Delhi and Goa were able to utilize more than 80 per cent of plant capacity over the entire study period. Maharashtra comes next. Over the entire sample period, in Maharashtra a high capacity utilization rate of 77 per cent is observed. However, it should be noted that in 1990-91 Maharashtra experienced a substantial decline. Relative to other states on an annual average Andhra Pradesh utilized the minimum plant capacity of 42 per cent during this period. Among other major industrial states both in Gujarat and Tamil Nadu around 60 per cent of plant capacity has been utilized during this period.

For most states capacity utilization rate declined over the pre-reform years. However, a noteworthy aspect of these pre-reform estimates at the state level is the steady decline in capacity utilization rate in West Bengal over the years 1970-71 through 1990-91. The annual capacity utilization rate of 90 per cent in 1970-71 dropped to 40 per cent in 1990-91. It should be noted that during this period West Bengal accounted for more than 60 per cent of total workdays lost in India (Shyam Sundar, 2004). Along with labor dispute, successive closures of industrial units (partially due to labor unrest) during this period possibly explain the observed decline in plant capacity utilization rate in this state. As discussed in Deb and Ray, 2013, during this period annual average manufacturing productivity in West Bengal also declined substantially. 
Over the entire post-reform period in most states average annual capacity utilization rate became lower. However, the capacity utilization growth rates for these states substantially improved after the reforms. Noticeable improvement was observed for the major states including Andhra Pradesh, Bihar, Gujarat, Maharashtra, Tamil Nadu, and West Bengal. Since West Bengal experienced decline in capacity utilization rate by around 4 per cent per year before the reforms, even though it grew by around 3 per cent per year after the reforms, the average annual capacity utilization rate in this state became around 57 per cent which was lower than its pre-reform estimates by more than 25 percentage points.

Estimates of net capacity utilization rates (see Table 2, 4, and 5 and Figures 5, 6, and 7) reveal a trend similar to what we observe from the estimates of gross capacity utilization rate both at the state and the national level. However, estimates from these two measures are substantially different reflecting the level of technical inefficiency or wasted capacity in Indian manufacturing. Also we find that growth rate in net capacity utilization (see Table 6) in post-reform period was substantially higher at the national as well as at the state level.

\section{Regression Analysis}

The empirical estimates of rates of productivity change presented in Table 7 show that at the individual level, most states enjoyed faster productivity growth after the reform (see Deb and Ray, 2013 for details). Despite the fact that some states experienced a slowdown in productivity growth or even a productivity decline after the reforms, manufacturing productivity grew faster during the post-reform period at the national level. Moreover, from Figure 8 we can see that both total factor productivity and capacity utilization rate followed similar growth path over the entire sample period at the national level.

Given the pro-cyclical nature of productivity, enhancement in plant capacity utilization through stimulation in demand for and removal of infrastructural bottlenecks in manufacturing production during the post-reform years could be the principal factor behind the observed acceleration in productivity 
growth in Indian manufacturing. If the impacts of economic reforms were channelized through a higher capacity utilization rate, no additional impact of reforms would be detected in a regression model once annual rates of change in capacity utilization was included as an explanatory variables. On the other hand, if other kind of structural changes, as mentioned before, from the reforms improved productivity, a simple dummy variable signifying the era of economic liberalization would come out to be statistically significant.

Therefore, to identify the role of economic reforms and capacity utilization growth in enhancing the productivity growth we estimate the following regression model using the information on productivity and capacity utilization growth for twenty major Indian states over the period 1970-71 through 2007-08.

$\operatorname{tfp} g_{i t}=\left(\alpha_{0}+\mu_{i}\right)+\alpha_{1} c u g_{i t}+\alpha_{2} r e f_{t}+v_{i t}$,

for $i=1,2,3, \ldots \ldots 20$, and $t=1971,1973,1974, \ldots \ldots \ldots, 2007$ and the disturbance term $v_{i t} \sim I I D\left(0, \sigma_{v}^{2}\right)$.

The dependent variable $t f p g_{i t}$ is the rate of change in total factor productivity in manufacturing for $i$ th state in year $t$ and is calculated as

$t f p g_{i t}=\left(m p i_{i t}-1\right) * 100$

where $m p i_{i t}$ is the Malmquist Index of total factor productivity for $i$ th state in year $t$.

To capture the marginal effect of reforms on productivity change in Indian manufacturing we include the qualitative variable $r e f_{t}$ in our econometric model. The dummy variable $r e f_{t}$ assumes the value 0 in the pre-reform period and 1 for the post-reform years.

The other explanatory variable $\mathrm{cug}_{i t}$ is the rate of change in capacity utilization for state $i$ in year $t$ and is calculated as $\operatorname{cug}_{i t}=\left(c u i_{i t}-1\right) * 100$.

where cui $_{i t}$ is the index of capacity utilization rate for $i$ th state in year $t$. 
There are some state specific time invariant factors such as geographical location, work-culture, and political climate which may influence productivity growth rate. Therefore, we include state specific factor $\mu_{i}$ into our model to capture possible unobserved heterogeneity across states. These factors are also very likely to be correlated with the capacity utilization growth rates in different states. So we estimate a oneway fixed effect model by within-effects estimation technique.

The estimated coefficients in the above model are reported in Table 8. We examine the impact of both gross and net capacity utilization growth rate separately by estimating the above specified regression model. Regression results show that the gross capacity utilization growth rate is positively related to productivity growth rate. For 1 per cent growth in gross capacity utilization rate, productivity growth rate is expected to increase by 0.16 per cent per year. Moreover, this marginal impact of gross capacity utilization growth rate is statistically significant at 1 per cent level.

On the other hand, even though the estimated regression coefficient implies that productivity growth rate increases by 0.02 per cent when net capacity utilization growth rate increases by 1 per cent, this impact is not statistically significant at 5 per cent or even at 10 per cent level. In fact, it has a p-value of 0.148 .

These results confirm that the better capacity utilization (presumably through demand stimulation and better access to essential inputs for production such as raw materials and capital goods) led to acceleration in manufacturing productivity growth over the post-reform years.

The coefficient of $r e f_{t}$ is positive showing that on average manufacturing productivity grew faster over the post-reform years even when capacity utilization is explicitly accounted for. When we control for of gross capacity utilization growth rate, estimated coefficient of $r e f_{t}$ shows that that after the year 1991 productivity growth rate increased by $0.88 \%$. This result is statistically significant at the 10 per cent level. We find a stronger effect of economic reforms when we use net measure of capacity utilization growth rate as the other explanatory variable. The estimated coefficient shows that on average, total factor 
productivity growth rate in Indian manufacturing is higher by 1.6 per cent per year after the reforms. This result is significant at 1 per cent level of significance.

The difference in the results across these two models is possibly due to the difference in the ways of measuring net and gross capacity utilization rate. The difference between net and gross capacity utilization rate is due to the difference resulting from including and not including the wasted capacity through technical inefficiency. So when we use net capacity utilization growth rate as an explanatory variable, then the technical inefficiency is captured by reforms. This possibly explains the stronger impact of reforms in the second model. Actually reform is enhancing productivity growth through improvement in technical efficiency.

\section{Conclusion}

In this paper we examine if all the impact of economic reforms of 1991 is channeled through better capacity utilization alone. We argued that structural changes resulting from reforms and better plant capacity utilization in manufacturing could be two possible (but not mutually exclusive) explanations for this accelerated productivity growth. Using the method of DEA we compute gross and net capacity utilization growth rate from the input-output data for major Indian states over the period 1970-71 through 2007-08. Empirical estimates of capacity utilization rates show that during the post-reform years annual average capacity utilization rate is lower for most of the states as well as for the country as a whole. However, after the reforms capacity utilization displayed a steady upward trend and growth rate in capacity utilization is substantially higher both at state and at the national level. A subsequent regression analysis confirms that there was evidence of a favorable impact of economic reforms on productivity growth in total manufacturing, beyond the positive impact of improved capacity utilization. 


\section{References}

[1] Aghion, P., Burgess, R., Redding, S., and Zilibotti, F. (2003). "The Unequal Effects of Liberalization: Theory and Evidence from India”, Unpublished, London School of Economics, London.

[2] Azeez, A.E. (2005). Economic Reforms and Industrial Performance: An Analysis of Capacity Utilization in Indian Manufacturing, Indian Journal of Economics and Business, 4(2): 305-223 (an earlier version is available as Working paper 334, Centre for Development Studies, Trivandrum, June, 2002, and Proceedings of the erc/metu VI international Conference in Economics, Ankara, Turkey, September 2002).

[3] Banker, R.D., Charnes, A., and Cooper, W.W. (1984). "Some Models for Estimating Technical and Scale Inefficiencies in Data Envelopment Analysis", Management Science, 30(9): 10781092.

[4] Berndt, E.R, and Morrison, C.J. (1981). "Capacity Utilization Measures: Underlying Economic Theory and an Alternative Approach, American Economic Review, American Economic Association 71(2): 48-52.

[5] Berndt, E.R., and Fuss, M.A. (1982). "Productivity Measurement Using Capital Asset Valuation to Adjust for Variations in Utilization”, NBER Working Paper No. 895, National Bureau of Economic Research, Inc.

[6] Berndt, E.R., and Fuss, M.A. (1986). "Productivity Measurement with Adjustments for Variations in Capacity Utilization and other Forms of Temporary Equilibrium”, Journal of Econometrics, Elsevier, 33(1-2): 7-29. 
[7] Cassels, J.M. (1937). "Excess Capacity and Monopolistic Competition", Quarterly Journal of Economics, 51(3): 426-443.

[8] Charnes, A., Cooper, W.W., and Rhodes, E. (1978). "Measuring the Efficiency of Decision Making Units", European Journal of Operational Research 2(6): 429-444.

[9] Corrado, C. and Mattey, J. (1997). "Capacity Utilization”, Journal of Economic Perspectives, 11(1): 151-167.

[10] Das, D.K. and Kalita, G. (2009). “Aggregate Productivity Growth in Indian Manufacturing: An Application of Domar Aggregation”, Working Papers 239, Indian Council for Research on International Economic Relations.

[11] Das, D.K. (2004). "Manufacturing Productivity under Varying Trade Regimes, 1980-2000", Economic and Political Weekly, 39 (5): 423-433.

[12] Deb, A.K. and Ray, S.C. (2013). "Economic Reforms and Total Factor Productivity Growth of Indian Manufacturing: An Inter-State Analysis”, Working Paper No. 2013-04, Department of Economics, University of Connecticut, USA

[13] Denison, E.F. (1974). “Accounting for United States economic growth, 1929-1969”, The Brooking Institution, Washington, D.C, USA.

[14] Färe, R., Grosskopf, S., and Kokkelenberg, E.C. (1989). "Measuring Plant Capacity, Utilization and Technical Change: A Nonparametric Approach", International Economic Review, 30 (3): 655-666.

[15] Gajanan, S. and Malhotra, D. (2007). "Measures of Capacity Utilization and its Determinants: A Study of Indian Manufacturing", Applied Economics, 39(6): 765-776. 
[16] Goldar, B.N. and Kumari, A. (2003). "Import liberalization and Productivity Growth in Indian Manufacturing Industries in the 1990s", The Developing Economies, 41: 436-460.

[17] Goldar, B.N. (2004). "Productivity Trends in Indian Manufacturing in the Pre and Post Reform Periods", Working Paper No. 137, Indian Council for Research on International Economic Relations, New Delhi.

[18] Goldar, B., and Renganathan, V.S. (2008). "Import Penetration and Capacity Utilization in Indian Industries”, Working Paper No. 293, Institute of Economic Growth, New Delhi, India.

[19] Hulten, C.R. (1986). "Productivity Change, Capacity Utilization, and the Sources of Efficiency Growth,” Journal of Econometrics, Elsevier, 33(1-2): 31-50.

[20] Johansen, L. (1968). "Production Functions and the Concept of Capacity", Recherches Recentessur la Function de Production, Collection Economic Mathematique et Econometrie, 2.

[21] Jorgenson, D.W. and Griliches, Z. (1967). "The Explanation of Productivity Change", Review of Economic Studies, 34: 249-282.

[22] Klein, L.R. (1960). "Some Theoretical Issues in the Measurement of Capacity", Econometrica, 28: $272-86$.

[23] Milner, C., Vencappa, D., and Wright, P. (2007). "Trade Policy and Productivity Growth in Indian Manufacturing", The World Economy, 30(2): 249-266.

[24] Morrison, C.J. (1986). "Productivity Measurement with Non-Static Expectations and Varying Capacity Utilization: An Integrated Approach”, Journal of Econometrics, Elsevier, vol. 33(1-2): 51-74. 
[25] Ray, S.C. (2002). "Did India's Economic Reforms Improve Efficiency and Productivity? A Nonparametric Analysis of the Initial Evidence from Manufacturing", Indian Economic Review, 37:23-57.

[26] Ray, S.C., Mukherjee, K., and Wu, Y. (2006). "Direct and Indirect Measures of Capacity Utilization: A Non-Parametric Analysis of Us Manufacturing”, Manchester School, University of Manchester, 74(4): 526-548.

[27] Saha, B. and Pan, I. (1994). "Industrial Disputes in India: An Empirical Analysis", Economic and Political Weekly, 29(18): 1081-87.

[28] Shapiro, M.D. (1989). “Assessing the Federal Reserve's Measures of Capacity and Utilization”, Brookings Papers on Economic Activity, 1989(1): 181-225.

[29] Shyam Sundar, K.R. (2004). "Lockouts in India, 1961-2001”, Economic and Political Weekly, 39 (39):4377-4385.

[30] Srinivasan, P.V. (1992). "Excess Capacities in Indian Industries: Supply or Demand Determined?", Economic and Political Weekly, 27 (45): 2437-2441 .

[31] Topalova, P. (2004). "Trade Liberalization and Firm Productivity: The Case of India", IMF Working Paper No. WP/04/28, International Monetary Fund, Washington DC.

[32] Trivedi, P., Prakash, A., and Sinate, D. (2000). "Productivity in Major Manufacturing Industries in India: 1973-74 to 1997-98”, Development Research Group study no. 2 (Mumbai: Department of Economic Analysis and Policy, Reserve Bank of India).

[33] Trivedi, P. (2004). “An Inter-State Perspective on Manufacturing Productivity in India: 1980-81 to 2000-01”, Indian Economic Review, 39(1): 203-337. 
[34] Trivedi, P., Lakshmanan, L. Jain, R., and Gupta, Y.K. (2011). "Productivity, Efficiency and Competitiveness of The Indian Manufacturing Sector", Development Research Group Study (Mumbai: Department of Economic Analysis and Policy, Reserve Bank of India).

[35] Uchikawa, S. (2001). "Investment Boom and Underutilization of Capacity in the 1990s", Economic and Political Weekly 36(34): 3247-54.-54.

[36] Unel, B. (2003). "Productivity Trends in India's Manufacturing Sectors in the Last Two Decades", IMF Working Paper No. WP/03/22, International Monetary Fund, Washington DC. 
Table 1 Average Annual Gross Capacity Utilization Rate in Indian Manufacturing (State-Wise)

\begin{tabular}{l||ccc}
\hline \hline \multicolumn{1}{l}{ States } & $\begin{array}{c}\text { Pre-Reform } \\
(1970-1991)\end{array}$ & $\begin{array}{c}\text { Post-Reform } \\
(1992-2007)\end{array}$ & $\begin{array}{c}\text { All Years } \\
(1970-2007)\end{array}$ \\
\hline \hline \multicolumn{1}{l}{ Andhra Pradesh } & 0.43 & 0.40 & 0.42 \\
Assam & 0.55 & 0.50 & 0.53 \\
Bihar & 0.71 & 0.62 & 0.67 \\
Chandigarh & 0.92 & 0.80 & 0.87 \\
Delhi & 0.73 & 0.89 & 0.80 \\
Goa & 0.81 & 0.81 & 0.81 \\
Gujarat & 0.66 & 0.54 & 0.61 \\
Haryana & 0.72 & 0.72 & 0.72 \\
Himachal Pradesh & 0.70 & 0.58 & 0.65 \\
Karnataka & 0.52 & 0.48 & 0.50 \\
Kerala & 0.57 & 0.62 & 0.59 \\
Madhya Pradesh & 0.66 & 0.63 & 0.65 \\
Maharashtra & 0.88 & 0.62 & 0.77 \\
Orissa & 0.62 & 0.47 & 0.56 \\
Pondicheri & 0.72 & 0.75 & 0.73 \\
Punjab & 0.45 & 0.58 & 0.51 \\
Rajasthan & 0.54 & 0.46 & 0.50 \\
Tamil Nadu & 0.67 & 0.48 & 0.59 \\
Uttar Pradesh & 0.55 & 0.48 & 0.52 \\
West Bengal & 0.81 & 0.47 & 0.66 \\
\hline All India & 0.65 & 0.59 & 0.62 \\
\hline \hline
\end{tabular}

Source: Author's own Calculations 
Table 2

Average Annual Net Capacity Utilization Rate in Indian Manufacturing (State-Wise)

\begin{tabular}{l||ccc}
\hline \hline \multicolumn{1}{l}{ States } & $\begin{array}{c}\text { Pre-Reform } \\
(1970-1991)\end{array}$ & $\begin{array}{c}\text { Post-Reform } \\
(1992-2007)\end{array}$ & $\begin{array}{c}\text { All Years } \\
(1970-2007)\end{array}$ \\
\hline \multicolumn{1}{l}{ Andhra Pradesh } & 0.49 & 0.47 & 0.48 \\
Assam & 0.61 & 0.56 & 0.59 \\
Bihar & 0.76 & 0.66 & 0.72 \\
Chandigarh & 0.93 & 0.82 & 0.88 \\
Delhi & 0.76 & 0.91 & 0.83 \\
Goa & 0.82 & 0.82 & 0.82 \\
Gujarat & 0.69 & 0.60 & 0.65 \\
Haryana & 0.77 & 0.78 & 0.78 \\
Himachal Pradesh & 0.70 & 0.62 & 0.67 \\
Karnataka & 0.56 & 0.52 & 0.55 \\
Kerala & 0.61 & 0.71 & 0.66 \\
Madhya Pradesh & 0.73 & 0.68 & 0.71 \\
Maharashtra & 0.87 & 0.65 & 0.78 \\
Orissa & 0.64 & 0.53 & 0.60 \\
Pondicheri & 0.76 & 0.78 & 0.76 \\
Punjab & 0.49 & 0.68 & 0.57 \\
Rajasthan & 0.61 & 0.52 & 0.57 \\
Tamil Nadu & 0.71 & 0.56 & 0.65 \\
Uttar Pradesh & 0.67 & 0.56 & 0.62 \\
West Bengal & 0.87 & 0.57 & 0.74 \\
\hline \hline All India & 0.69 & 0.65 & 0.67 \\
\hline \hline
\end{tabular}

Source: Author's own Calculations 
Table 3

Average Annual Rates of Change in Gross Capacity Utilization Rate in Indian Manufacturing (State-Wise)

\begin{tabular}{|c|c|c|c|}
\hline States & $\begin{array}{l}\text { Pre-Reform } \\
(1970-1991)\end{array}$ & $\begin{array}{c}\text { Post-Reform } \\
(1992-2007)\end{array}$ & $\begin{array}{c}\text { All Years } \\
(1970-2007)\end{array}$ \\
\hline Andhra Pradesh & -5.34 & 6.69 & -0.17 \\
\hline Assam & -1.23 & 3.77 & 0.96 \\
\hline Bihar & -3.10 & 4.19 & 0.07 \\
\hline Chandigarh & 0.30 & -1.25 & -0.39 \\
\hline Delhi & 1.40 & 0.85 & 1.16 \\
\hline Goa & 3.49 & 1.43 & 2.57 \\
\hline Gujarat & -3.84 & 4.89 & -0.05 \\
\hline Haryana & -3.77 & 4.34 & -0.25 \\
\hline Himachal Pradesh & -1.69 & 1.18 & -0.42 \\
\hline Karnataka & -1.19 & 2.49 & 0.43 \\
\hline Kerala & -2.94 & 5.13 & 0.57 \\
\hline Madhya Pradesh & -1.97 & 2.48 & -0.01 \\
\hline Maharashtra & -3.35 & 3.04 & -0.56 \\
\hline Orissa & -0.88 & 1.35 & 0.10 \\
\hline Pondicheri & -3.52 & 4.70 & 0.05 \\
\hline Punjab & -2.42 & 4.66 & 0.67 \\
\hline Rajasthan & -3.10 & 2.82 & -0.52 \\
\hline Tamil Nadu & -3.42 & 2.97 & -0.63 \\
\hline Uttar Pradesh & -3.37 & 2.95 & -0.61 \\
\hline West Bengal & -3.92 & 2.60 & -1.07 \\
\hline All India & -0.57 & 4.56 & 1.68 \\
\hline
\end{tabular}

Source: Author's own Calculations 
Table 4

Average Annual Rates of Change in Net Capacity Utilization Rate in Indian Manufacturing (State-Wise)

\begin{tabular}{|c|c|c|c|}
\hline States & $\begin{array}{c}\text { Pre-Reform } \\
(1970-1991)\end{array}$ & $\begin{array}{c}\text { Post-Reform } \\
\text { (1992-2007) }\end{array}$ & $\begin{array}{c}\text { All Years } \\
(1970-2007)\end{array}$ \\
\hline Andhra Pradesh & -5.63 & 7.57 & 0.02 \\
\hline Assam & -1.73 & 3.84 & 0.71 \\
\hline Bihar & -3.03 & 4.09 & 0.07 \\
\hline Chandigarh & 0.30 & -1.25 & -0.39 \\
\hline Delhi & 0.95 & 0.85 & 0.91 \\
\hline Goa & 2.81 & 1.43 & 2.20 \\
\hline Gujarat & -3.65 & 4.57 & -0.08 \\
\hline Haryana & -3.43 & 4.09 & -0.16 \\
\hline Himachal Pradesh & -1.69 & 1.18 & -0.42 \\
\hline Karnataka & -1.18 & 2.97 & 0.65 \\
\hline Kerala & -3.29 & 5.49 & 0.52 \\
\hline Madhya Pradesh & -2.05 & 2.56 & -0.03 \\
\hline Maharashtra & -3.31 & 2.99 & -0.56 \\
\hline Orissa & -0.75 & 1.87 & 0.41 \\
\hline Pondicheri & -3.71 & 4.20 & -0.27 \\
\hline Punjab & -1.81 & 4.89 & 1.12 \\
\hline Rajasthan & -3.18 & 4.01 & -0.04 \\
\hline Tamil Nadu & -3.76 & 3.74 & -0.50 \\
\hline Uttar Pradesh & -3.59 & 3.26 & -0.60 \\
\hline West Bengal & -3.40 & 2.86 & -0.67 \\
\hline All India & -0.68 & 4.56 & 1.62 \\
\hline
\end{tabular}

Source: Author's own Calculations 
Table $5^{8}$

Annual Gross Capacity Utilization Rate in Indian Manufacturing (State-Wise)

\begin{tabular}{|c|c|c|c|c|c|c|c|c|c|c|c|c|c|c|c|c|}
\hline States & AP & BI & $\mathrm{CH}$ & GU & HA & KA & KE & $\mathrm{MH}$ & MP & POR & $\mathrm{PU}$ & RA & TN & UP & WB & All India \\
\hline 1970 & 0.47 & 0.89 & 0.94 & 0.73 & 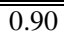 & 0.53 & 0.62 & 0.94 & 0.67 & 0.62 & 0.46 & 0.62 & "0.65 & "0.68 & "0.90 & 0.65 \\
\hline 1971 & 0.52 & 0.88 & 0.95 & 0.76 & 1.00 & 0.55 & 0.59 & 0.99 & 0.75 & 0.64 & 0.39 & 0.68 & 0.70 & 0.72 & 0.96 & 0.73 \\
\hline 1973 & 0.51 & 0.72 & 0.69 & 0.66 & 0.78 & 0.47 & 0.42 & 0.96 & 0.70 & 0.49 & 0.38 & 0.57 & 0.57 & 0.58 & 0.94 & 0.61 \\
\hline 1974 & 0.54 & 0.94 & 0.78 & 0.75 & 0.84 & 0.51 & 0.52 & 1.00 & 0.70 & 0.64 & 0.42 & 0.63 & 0.69 & 0.58 & 0.82 & 0.69 \\
\hline 1975 & 0.60 & 0.77 & 0.96 & 0.68 & 0.75 & 0.53 & 0.60 & 1.00 & 0.69 & 0.62 & 0.43 & 0.60 & 0.74 & 0.77 & 0.96 & 0.69 \\
\hline 1976 & 0.50 & 0.68 & 1.00 & 0.65 & 0.77 & 0.51 & 0.64 & 0.97 & 0.70 & 0.62 & 0.43 & 0.58 & 0.75 & 0.67 & 0.95 & 0.68 \\
\hline 1977 & 0.44 & 0.61 & 0.96 & 0.70 & 0.71 & 0.53 & 0.60 & 0.98 & 0.62 & 0.53 & 0.45 & 0.55 & 0.78 & 0.53 & 0.94 & 0.66 \\
\hline 1978 & 0.46 & 0.72 & 1.00 & 0.70 & 0.87 & 0.58 & 0.66 & 1.00 & 0.67 & 0.72 & 0.51 & 0.62 & 0.83 & 0.54 & 0.98 & 0.71 \\
\hline 1979 & 0.41 & 0.61 & 1.00 & 0.73 & 0.77 & 0.59 & 0.64 & 0.98 & 0.64 & 0.74 & 0.49 & 0.60 & 0.85 & 0.54 & 0.95 & 0.67 \\
\hline 1980 & 0.42 & 0.65 & 0.95 & 0.76 & 0.75 & 0.57 & 0.77 & 0.94 & 0.66 & 0.64 & 0.52 & 0.58 & 0.86 & 0.52 & 0.95 & 0.70 \\
\hline 1981 & 0.42 & 0.66 & 1.00 & 0.80 & 0.83 & 0.62 & 0.83 & 0.97 & 0.64 & 0.62 & 0.59 & 0.54 & 0.88 & 0.60 & 0.88 & 0.71 \\
\hline 1982 & 0.53 & 0.87 & 0.93 & 0.90 & 0.84 & 0.65 & 0.72 & 1.00 & 0.69 & 0.54 & 0.60 & 0.50 & 0.89 & 0.58 & 0.89 & 0.75 \\
\hline 1983 & 0.54 & 0.84 & 1.00 & 0.84 & 0.78 & 0.67 & 0.64 & 0.99 & 0.72 & 0.53 & 0.55 & 0.55 & 0.80 & 0.56 & 0.88 & 0.73 \\
\hline 1984 & 0.55 & 0.75 & 0.78 & 0.79 & 0.72 & 0.64 & 0.63 & 0.93 & 0.76 & 0.64 & 0.55 & 0.56 & 0.78 & 0.60 & 0.89 & 0.70 \\
\hline 1985 & 0.48 & 0.60 & 0.95 & 0.74 & 0.65 & 0.57 & 0.57 & 0.90 & 0.65 & 0.63 & 0.54 & 0.55 & 0.69 & 0.53 & 0.77 & 0.67 \\
\hline 1986 & 0.46 & 0.75 & 0.86 & 0.69 & 0.65 & 0.57 & 0.60 & 0.84 & 0.81 & 0.68 & 0.52 & 0.59 & 0.67 & 0.60 & 0.79 & 0.69 \\
\hline 1987 & 0.39 & 0.79 & 0.80 & 0.55 & 0.67 & 0.47 & 0.53 & 0.75 & 0.80 & 0.62 & 0.48 & 0.51 & 0.55 & 0.55 & 0.72 & 0.63 \\
\hline 1988 & 0.29 & 0.69 & 0.88 & 0.43 & 0.56 & 0.35 & 0.39 & 0.62 & 0.58 & 0.73 & 0.34 & 0.42 & 0.37 & 0.42 & 0.54 & 0.54 \\
\hline 1989 & 0.23 & 0.53 & 1.00 & 0.39 & 0.46 & 0.34 & 0.43 & 0.78 & 0.45 & 0.70 & 0.33 & 0.38 & 0.34 & 0.38 & 0.44 & 0.49 \\
\hline 1990 & 0.15 & 0.57 & 0.95 & 0.35 & 0.44 & 0.33 & 0.29 & 0.54 & 0.49 & 0.55 & 0.28 & 0.36 & 0.31 & 0.36 & 0.40 & 0.46 \\
\hline 1991 & 0.16 & 0.47 & 1.00 & 0.34 & 0.42 & 0.42 & 0.34 & 0.48 & 0.45 & 0.52 & 0.28 & 0.33 & 0.32 & 0.34 & 0.41 & 0.47 \\
\hline 1992 & 0.19 & 0.46 & 1.00 & 0.42 & 0.48 & 0.40 & 0.40 & 0.53 & 0.60 & 0.55 & 0.33 & 0.34 & 0.36 & 0.37 & 0.40 & 0.48 \\
\hline 1993 & 0.24 & 0.56 & 1.00 & 0.43 & 0.51 & 0.45 & 0.39 & 0.53 & 0.66 & 0.55 & 0.38 & 0.43 & 0.40 & 0.42 & 0.42 & 0.53 \\
\hline 1994 & 0.29 & 0.46 & 0.93 & 0.43 & 0.59 & 0.47 & 0.38 & 0.55 & 0.71 & 0.47 & 0.40 & 0.35 & 0.41 & 0.41 & 0.40 & 0.52 \\
\hline 1995 & 0.35 & 0.42 & 0.98 & 0.43 & 0.63 & 0.47 & 0.45 & 0.50 & 0.63 & 0.47 & 0.38 & 0.35 & 0.43 & 0.37 & 0.34 & 0.50 \\
\hline 1996 & 0.35 & 0.49 & 0.62 & 0.46 & 0.73 & 0.51 & 0.61 & 0.54 & 0.57 & 0.43 & 0.44 & 0.41 & 0.47 & 0.44 & 0.38 & 0.54 \\
\hline 1997 & 0.43 & 0.64 & 0.80 & 0.53 & 0.85 & 0.52 & 0.58 & 0.69 & 0.67 & 0.51 & 0.55 & 0.55 & 0.58 & 0.51 & 0.49 & 0.60 \\
\hline 1998 & 0.42 & 0.53 & 0.84 & 0.49 & 0.76 & 0.40 & 0.66 & 0.71 & 0.54 & 0.41 & 0.68 & 0.49 & 0.47 & 0.35 & 0.70 & 0.63 \\
\hline 1999 & 0.42 & 0.69 & 0.65 & 0.51 & 0.71 & 0.38 & 0.67 & 0.60 & 0.85 & 0.47 & 0.67 & 0.37 & 0.48 & 0.37 & 0.41 & 0.61 \\
\hline 2000 & 0.47 & 0.77 & 0.60 & 0.53 & 0.72 & 0.42 & 0.72 & 0.64 & 0.67 & 0.47 & 0.72 & 0.49 & 0.55 & 0.43 & 0.50 & 0.61 \\
\hline 2001 & 0.46 & 0.67 & 0.66 & 0.59 & 0.76 & 0.45 & 0.65 & 0.65 & 0.73 & 0.44 & 0.82 & 0.51 & 0.56 & 0.53 & 0.44 & 0.63 \\
\hline 2002 & 0.53 & 0.53 & 0.69 & 0.69 & 0.82 & 0.48 & 0.72 & 0.66 & 0.65 & 0.44 & 0.69 & 0.52 & 0.51 & 0.62 & 0.46 & 0.63 \\
\hline 2003 & 0.42 & 0.50 & 0.71 & 0.59 & 0.76 & 0.44 & 0.72 & 0.54 & 0.59 & 0.40 & 0.76 & 0.48 & 0.49 & 0.57 & 0.41 & 0.59 \\
\hline 2004 & 0.44 & 0.61 & 0.73 & 0.54 & 0.74 & 0.47 & 0.70 & 0.62 & 0.45 & 0.38 & 0.72 & 0.47 & 0.48 & 0.55 & 0.48 & 0.58 \\
\hline 2005 & 0.43 & 0.80 & 0.94 & 0.61 & 0.79 & 0.54 & 0.76 & 0.66 & 0.50 & 0.42 & 0.59 & 0.49 & 0.47 & 0.51 & 0.52 & 0.63 \\
\hline 2006 & 0.47 & 0.85 & 0.87 & 0.69 & 0.84 & 0.65 & 0.76 & 0.79 & 0.62 & 0.51 & 0.56 & 0.52 & 0.52 & 0.63 & 0.63 & 0.70 \\
\hline 2007 & 0.44 & 0.91 & 0.82 & 0.72 & 0.82 & 0.62 & 0.76 & 0.77 & 0.66 & 0.64 & 0.58 & 0.51 & 0.52 & 0.55 & 0.61 & 0.70 \\
\hline Annual Average & 0.42 & 0.67 & 0.87 & 0.61 & 0.72 & 0.50 & 0.59 & 0.77 & 0.65 & 0.56 & 0.51 & 0.50 & 0.59 & 0.52 & 0.66 & 0.62 \\
\hline
\end{tabular}

Source: Author's own Calculations

${ }^{8}$ See appendix to this paper for the acronyms used for Indian states. 
Table 6

Annual Net Capacity Utilization Rate in Indian Manufacturing (State-Wise)

\begin{tabular}{|c|c|c|c|c|c|c|c|c|c|c|c|c|c|c|c|c|}
\hline States & AP & BI & $\mathrm{CH}$ & $\mathrm{GU}$ & HA & KA & $\mathrm{KE}$ & $\mathrm{MH}$ & MP & OR & $\overline{P U}$ & RA & TN & UP & WB & All India \\
\hline 1970 & 0.52 & 0.89 & 0.94 & 0.76 & 0.92 & 0.53 & 0.67 & 0.94 & 0.73 & 0.62 & 0.46 & 0.66 & 0.72 & 0.75 & 0.91 & 0.69 \\
\hline 1971 & 0.68 & 0.89 & 0.95 & 0.83 & 1.00 & 0.62 & 0.73 & 0.99 & 0.82 & 0.67 & 0.41 & 0.79 & 0.85 & 0.85 & 0.99 & 0.79 \\
\hline 1973 & 0.62 & 0.84 & 0.69 & 0.69 & 0.89 & 0.57 & 0.50 & 0.96 & 0.82 & 0.52 & 0.38 & 0.69 & 0.67 & 0.75 & 0.94 & 0.68 \\
\hline 1974 & 0.66 & 1.00 & 0.78 & 0.75 & 0.84 & 0.60 & 0.56 & 1.00 & 0.82 & 0.74 & 0.42 & 0.73 & 0.74 & 0.82 & 0.82 & 0.74 \\
\hline 1975 & 0.74 & 0.93 & 0.96 & 0.70 & 0.77 & 0.65 & 0.65 & 1.00 & 0.85 & 0.71 & 0.43 & 0.72 & 0.88 & 0.95 & 0.96 & 0.76 \\
\hline 1976 & 0.59 & 0.74 & 1.00 & 0.67 & 0.77 & 0.56 & 0.69 & 0.97 & 0.74 & 0.62 & 0.43 & 0.64 & 0.82 & 0.81 & 0.95 & 0.72 \\
\hline 1977 & 0.50 & 0.73 & 0.96 & 0.70 & 0.73 & 0.58 & 0.65 & 1.00 & 0.70 & 0.53 & 0.45 & 0.61 & 0.83 & 0.69 & 0.94 & 0.70 \\
\hline 1978 & 0.50 & 0.82 & 1.00 & 0.70 & 0.87 & 0.59 & 0.66 & 1.00 & 0.80 & 0.72 & 0.51 & 0.70 & 0.85 & 0.67 & 0.98 & 0.74 \\
\hline 1979 & 0.45 & 0.69 & 1.00 & 0.77 & 0.79 & 0.62 & 0.68 & 0.99 & 0.70 & 0.74 & 0.49 & 0.65 & 0.89 & 0.66 & 0.99 & 0.71 \\
\hline 1980 & 0.46 & 0.82 & 0.95 & 0.77 & 0.77 & 0.60 & 0.79 & 0.95 & 0.73 & 0.67 & 0.52 & 0.63 & 0.90 & 0.65 & 0.95 & 0.74 \\
\hline 1981 & 0.47 & 0.73 & 1.00 & 0.81 & 0.90 & 0.66 & 0.83 & 0.98 & 0.72 & 0.63 & 0.62 & 0.62 & 0.93 & 0.66 & 0.94 & 0.75 \\
\hline 1982 & 0.61 & 0.87 & 0.94 & 0.90 & 0.95 & 0.72 & 0.72 & 1.00 & 0.78 & 0.54 & 0.70 & 0.64 & 0.95 & 0.74 & 0.97 & 0.81 \\
\hline 1983 & 0.55 & 0.85 & 1.00 & 0.87 & 0.86 & 0.72 & 0.68 & 1.00 & 0.82 & 0.57 & 0.66 & 0.62 & 0.90 & 0.68 & 0.99 & 0.79 \\
\hline 1984 & 0.62 & 0.77 & 0.85 & 0.79 & 0.78 & 0.66 & 0.66 & 0.93 & 0.80 & 0.73 & 0.63 & 0.63 & 0.80 & 0.69 & 0.95 & 0.75 \\
\hline 1985 & 0.53 & 0.61 & 0.95 & 0.79 & 0.74 & 0.60 & 0.59 & 0.90 & 0.65 & 0.70 & 0.62 & 0.62 & 0.75 & 0.62 & 0.91 & 0.71 \\
\hline 1986 & 0.49 & 0.78 & 0.86 & 0.70 & 0.73 & 0.58 & 0.62 & 0.85 & 0.84 & 0.72 & 0.58 & 0.61 & 0.70 & 0.64 & 0.94 & 0.72 \\
\hline 1987 & 0.39 & 0.79 & 0.80 & 0.55 & 0.73 & 0.48 & 0.53 & 0.75 & 0.80 & 0.66 & 0.52 & 0.56 & 0.56 & 0.58 & 0.89 & 0.65 \\
\hline 1988 & 0.30 & 0.69 & 0.88 & 0.56 & 0.69 & 0.40 & 0.55 & 0.31 & 0.67 & 0.51 & 0.45 & 0.42 & 0.22 & 0.67 & 0.73 & 0.55 \\
\hline 1989 & 0.27 & 0.58 & 1.00 & 0.44 & 0.50 & 0.36 & 0.45 & 0.79 & 0.48 & 0.73 & 0.38 & 0.46 & 0.37 & 0.42 & 0.53 & 0.53 \\
\hline 1990 & 0.17 & 0.57 & 0.95 & 0.38 & 0.49 & 0.34 & 0.30 & 0.55 & 0.52 & 0.60 & 0.33 & 0.41 & 0.33 & 0.40 & 0.46 & 0.48 \\
\hline 1991 & 0.16 & 0.48 & 1.00 & 0.36 & 0.46 & 0.42 & 0.35 & 0.48 & 0.48 & 0.53 & 0.32 & 0.34 & 0.33 & 0.36 & 0.45 & 0.49 \\
\hline 1992 & 0.20 & 0.48 & 1.00 & 0.46 & 0.57 & 0.42 & 0.43 & 0.55 & 0.63 & 0.58 & 0.40 & 0.38 & 0.40 & 0.42 & 0.47 & 0.52 \\
\hline 1993 & 0.27 & 0.56 & 1.00 & 0.48 & 0.60 & 0.49 & 0.43 & 0.55 & 0.69 & 0.60 & 0.48 & 0.49 & 0.42 & 0.47 & 0.49 & 0.57 \\
\hline 1994 & 0.29 & 0.48 & 0.93 & 0.45 & 0.64 & 0.48 & 0.41 & 0.55 & 0.72 & 0.48 & 0.47 & 0.37 & 0.42 & 0.43 & 0.44 & 0.53 \\
\hline 1995 & 0.35 & 0.42 & 0.99 & 0.45 & 0.68 & 0.48 & 0.51 & 0.51 & 0.63 & 0.47 & 0.46 & 0.37 & 0.44 & 0.41 & 0.38 & 0.53 \\
\hline 1996 & 0.39 & 0.52 & 0.73 & 0.50 & 0.83 & 0.57 & 0.74 & 0.60 & 0.62 & 0.49 & 0.55 & 0.48 & 0.54 & 0.50 & 0.47 & 0.60 \\
\hline 1997 & 0.49 & 0.65 & 0.86 & 0.60 & 0.96 & 0.58 & 0.74 & 0.74 & 0.68 & 0.54 & 0.73 & 0.64 & 0.70 & 0.60 & 0.60 & 0.67 \\
\hline 1998 & 0.57 & 0.65 & 0.84 & 0.53 & 0.83 & 0.43 & 0.84 & 0.73 & 0.65 & 0.49 & 0.78 & 0.60 & 0.56 & 0.45 & 0.80 & 0.71 \\
\hline 1999 & 0.53 & 0.74 & 0.65 & 0.57 & 0.77 & 0.44 & 0.73 & 0.62 & 0.87 & 0.54 & 0.75 & 0.41 & 0.56 & 0.46 & 0.54 & 0.68 \\
\hline 2000 & 0.57 & 0.88 & 0.67 & 0.61 & 0.79 & 0.45 & 0.84 & 0.66 & 0.71 & 0.54 & 0.83 & 0.52 & 0.61 & 0.51 & 0.60 & 0.68 \\
\hline 2001 & 0.54 & 0.83 & 0.66 & 0.69 & 0.82 & 0.47 & 0.78 & 0.68 & 0.76 & 0.51 & 0.88 & 0.54 & 0.63 & 0.61 & 0.52 & 0.69 \\
\hline 2002 & 0.62 & 0.55 & 0.69 & 0.79 & 0.86 & 0.49 & 0.85 & 0.69 & 0.70 & 0.52 & 0.79 & 0.57 & 0.59 & 0.70 & 0.54 & 0.68 \\
\hline 2003 & 0.52 & 0.62 & 0.71 & 0.67 & 0.78 & 0.51 & 0.78 & 0.58 & 0.65 & 0.48 & 0.81 & 0.53 & 0.56 & 0.66 & 0.50 & 0.64 \\
\hline 2004 & 0.55 & 0.68 & 0.80 & 0.61 & 0.78 & 0.54 & 0.80 & 0.62 & 0.55 & 0.47 & 0.85 & 0.54 & 0.58 & 0.66 & 0.60 & 0.65 \\
\hline 2005 & 0.55 & 0.80 & 0.94 & 0.67 & 0.87 & 0.62 & 0.86 & 0.71 & 0.62 & 0.52 & 0.76 & 0.59 & 0.60 & 0.66 & 0.68 & 0.71 \\
\hline 2006 & 0.56 & 0.85 & 0.87 & 0.74 & 0.91 & 0.70 & 0.83 & 0.81 & 0.70 & 0.59 & 0.70 & 0.59 & 0.79 & 0.75 & 0.79 & 0.76 \\
\hline 2007 & 0.52 & 0.91 & 0.82 & 0.74 & 0.87 & 0.67 & 0.81 & 0.77 & 0.72 & 0.71 & 0.68 & 0.65 & 0.60 & 0.60 & 0.71 & 0.74 \\
\hline Annual Average & 0.52 & 0.59 & 0.88 & 0.83 & 0.78 & 0.67 & 0.66 & 0.78 & "0.71 & 0.6 & 0.76 & 0.57 & 0.65 & 0.62 & 0.74 & 0.67 \\
\hline
\end{tabular}

Source: Author's own Calculations 
Table 7

Average Annual Rates of Total Factor Productivity Change in Indian Manufacturing (State-Wise)

\begin{tabular}{|c|c|c|c|}
\hline States & $\begin{array}{l}\text { Pre-Reform } \\
(1970-1991)\end{array}$ & $\begin{array}{l}\text { Post-Reform } \\
(1992-2007)\end{array}$ & $\begin{array}{c}\text { All Years } \\
(1970-2007)\end{array}$ \\
\hline Andhra Pradesh & -0.068 & 3.202 & 1.372 \\
\hline Assam & 1.256 & 3.322 & 2.169 \\
\hline Bihar & 2.495 & 2.155 & 2.344 \\
\hline Chandigarh & -0.642 & 3.012 & 0.966 \\
\hline Delhi & 1.890 & 1.559 & 1.743 \\
\hline Goa & 2.322 & 2.028 & 2.191 \\
\hline Gujarat & 0.896 & 3.609 & 2.093 \\
\hline Haryana & 1.481 & 4.322 & 2.734 \\
\hline Himachal Pradesh & 0.839 & 2.583 & 1.611 \\
\hline Karnataka & 1.086 & 2.771 & 1.831 \\
\hline Kerala & 0.872 & 4.315 & 2.388 \\
\hline Madhya Pradesh & 2.138 & 1.014 & 1.637 \\
\hline Maharashtra & 0.943 & 2.244 & 1.519 \\
\hline Orissa & 0.758 & 3.243 & 1.855 \\
\hline Pondicheri & 0.985 & -0.515 & 0.315 \\
\hline Punjab & -0.253 & 2.287 & 0.868 \\
\hline Rajasthan & 1.584 & 3.580 & 2.467 \\
\hline Tamil Nadu & 1.400 & 2.878 & 2.054 \\
\hline Uttar Pradesh & 1.530 & 2.820 & 2.101 \\
\hline West Bengal & -0.240 & 2.736 & 1.072 \\
\hline All India & 1.064 & 2.737 & 1.986 \\
\hline
\end{tabular}

Source: Deb and Ray, 2013 
Table 8: Regression Results

\begin{tabular}{lcc}
\hline \hline Variables & Model 1 & Model 2 \\
\hline cugr (Gross) & $0.17^{* * *}$ & - \\
& $(0.02)$ & \\
cugr (Net) & - & 0.03 \\
& & $(0.01)$ \\
Ref & $0.87^{* *}$ & $1.60^{* * *}$ \\
& $(.54)$ & $(0.58)$ \\
Cons & $1.43^{* * *}$ & $1.30^{* * *}$ \\
& $(0.35)$ & $(0.38)$ \\
$R^{2}$ & & 0.02 \\
\hline \hline
\end{tabular}

Note: $\mathrm{n}=20, \mathrm{~T}=36$,

***: significant at $1 \%$ level of significance,

*: significant at $10 \%$ level of significance.

Figures in parentheses represent standard error of coefficients.

Source: Author's own Calculations 


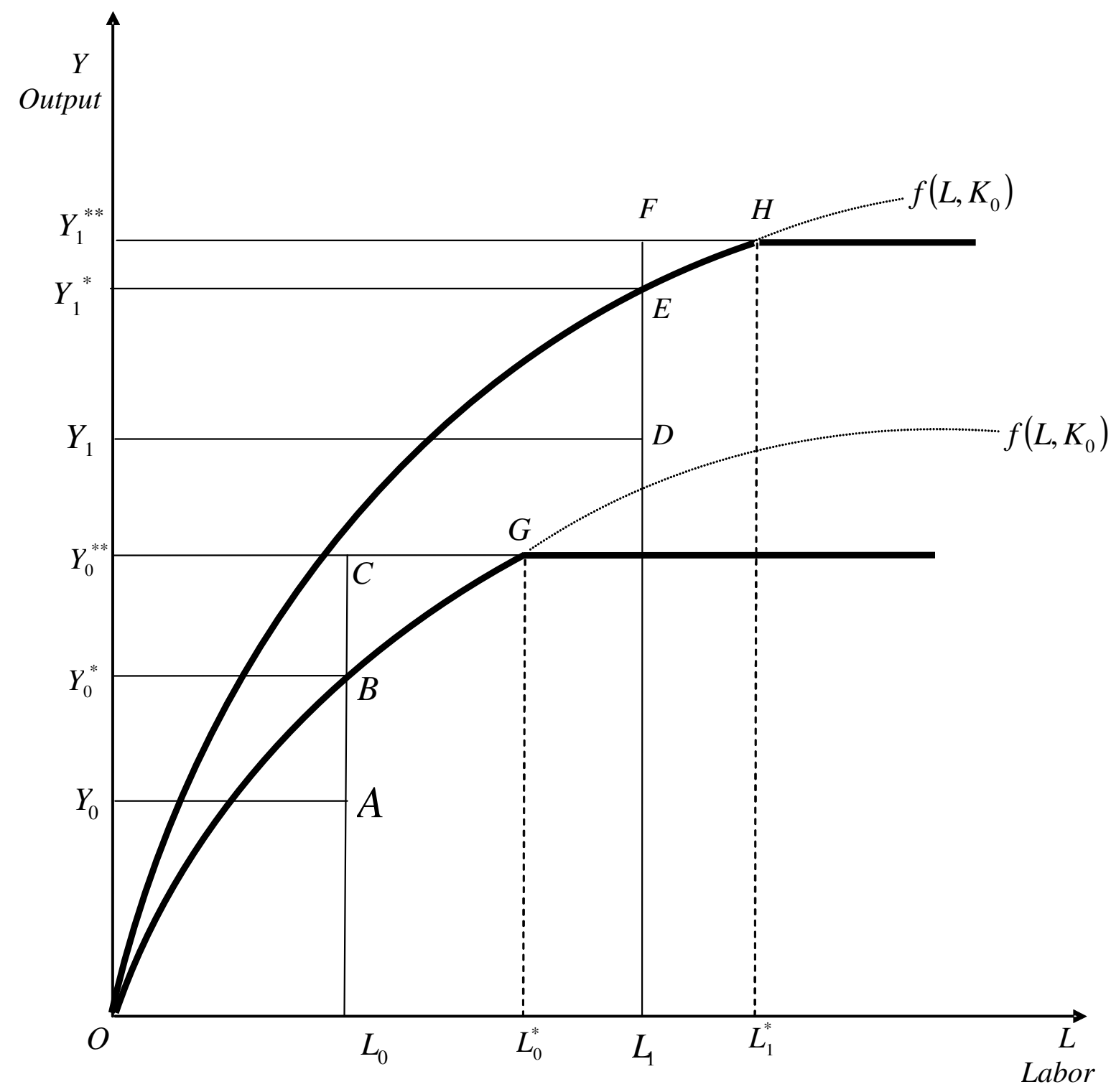

Figure 1: Measure of Gross and Net Capacity Utilization Rate 


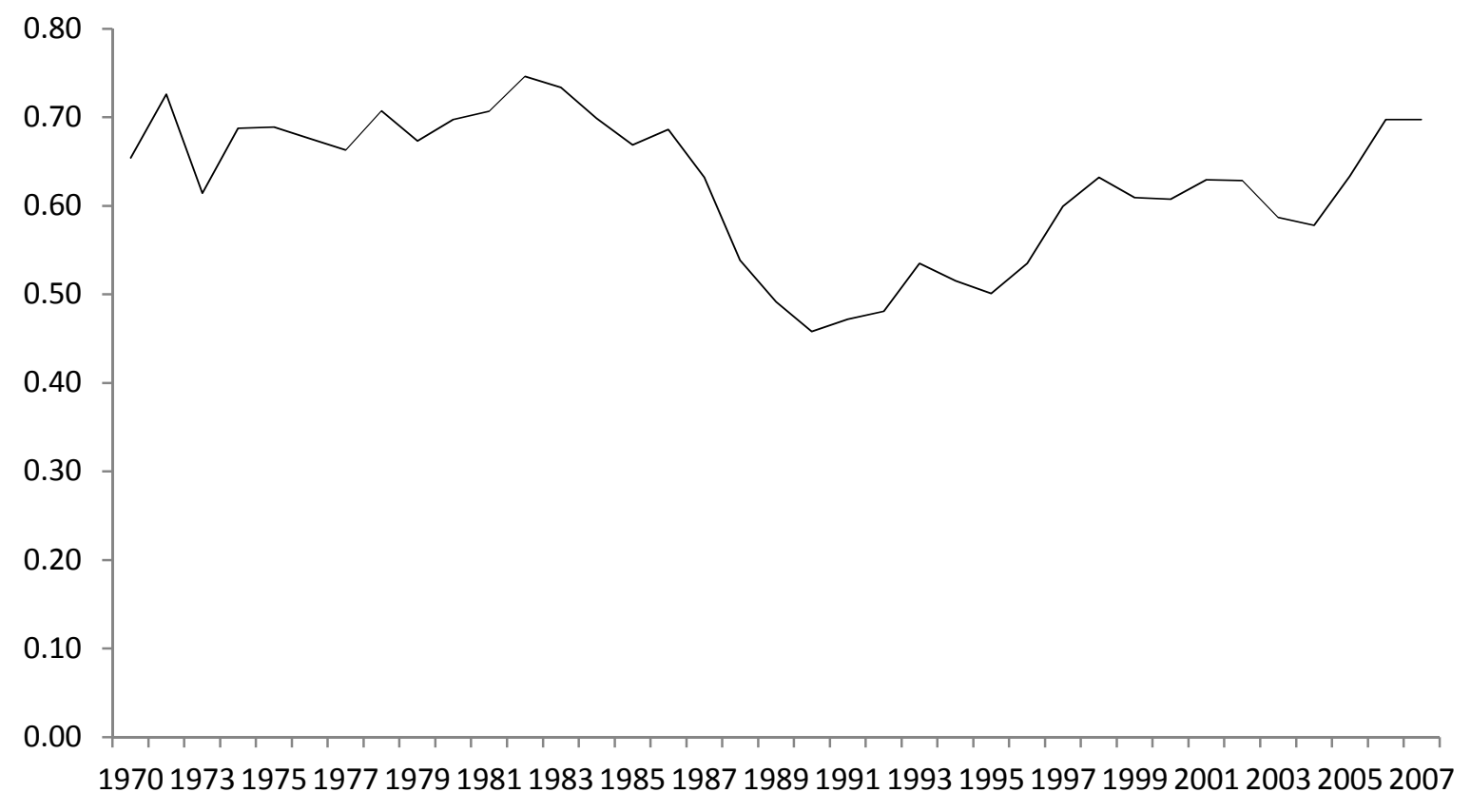

Figure 2: Gross Capacity Utilization Rate (1970-71 to 2007-08) in Indian Manufacturing Source: Author's own Calculations 


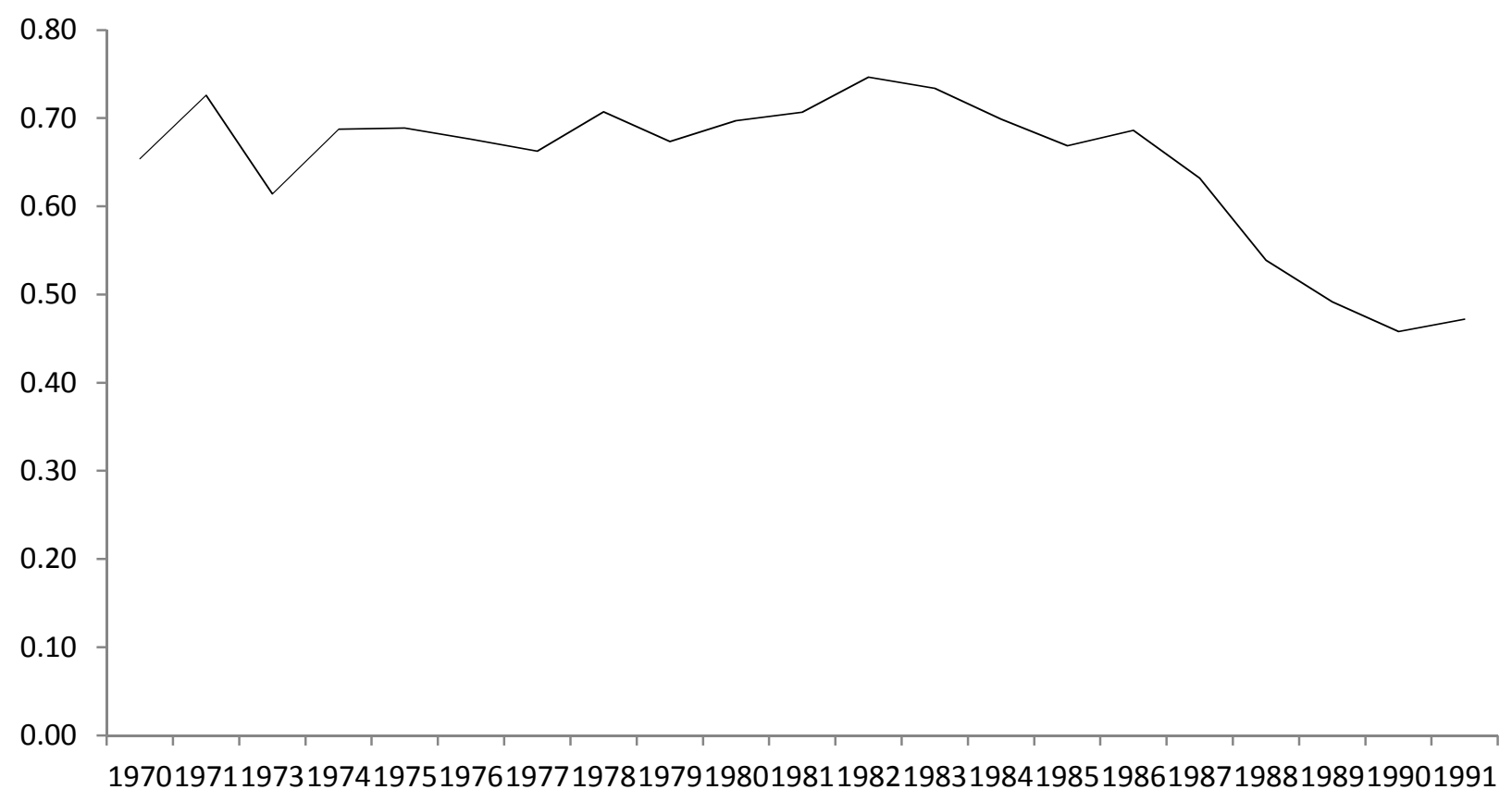

Figure 3: Gross Capacity Utilization Rate (Pre-Reform) in Indian Manufacturing Source: Author's own Calculations 


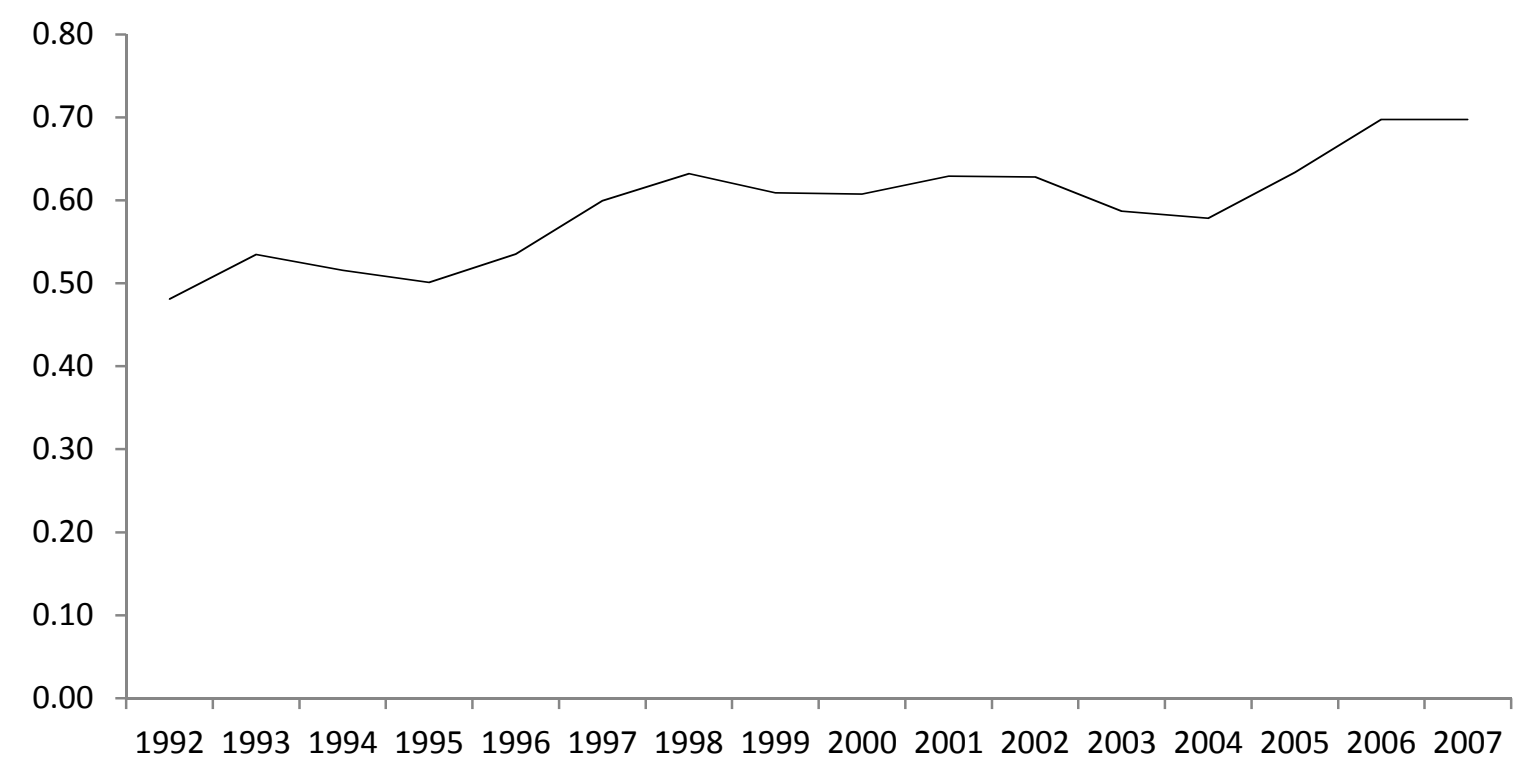

Figure 4: Gross Capacity Utilization Rate (Post-Reform) in Indian Manufacturing Source: Author's own Calculations 


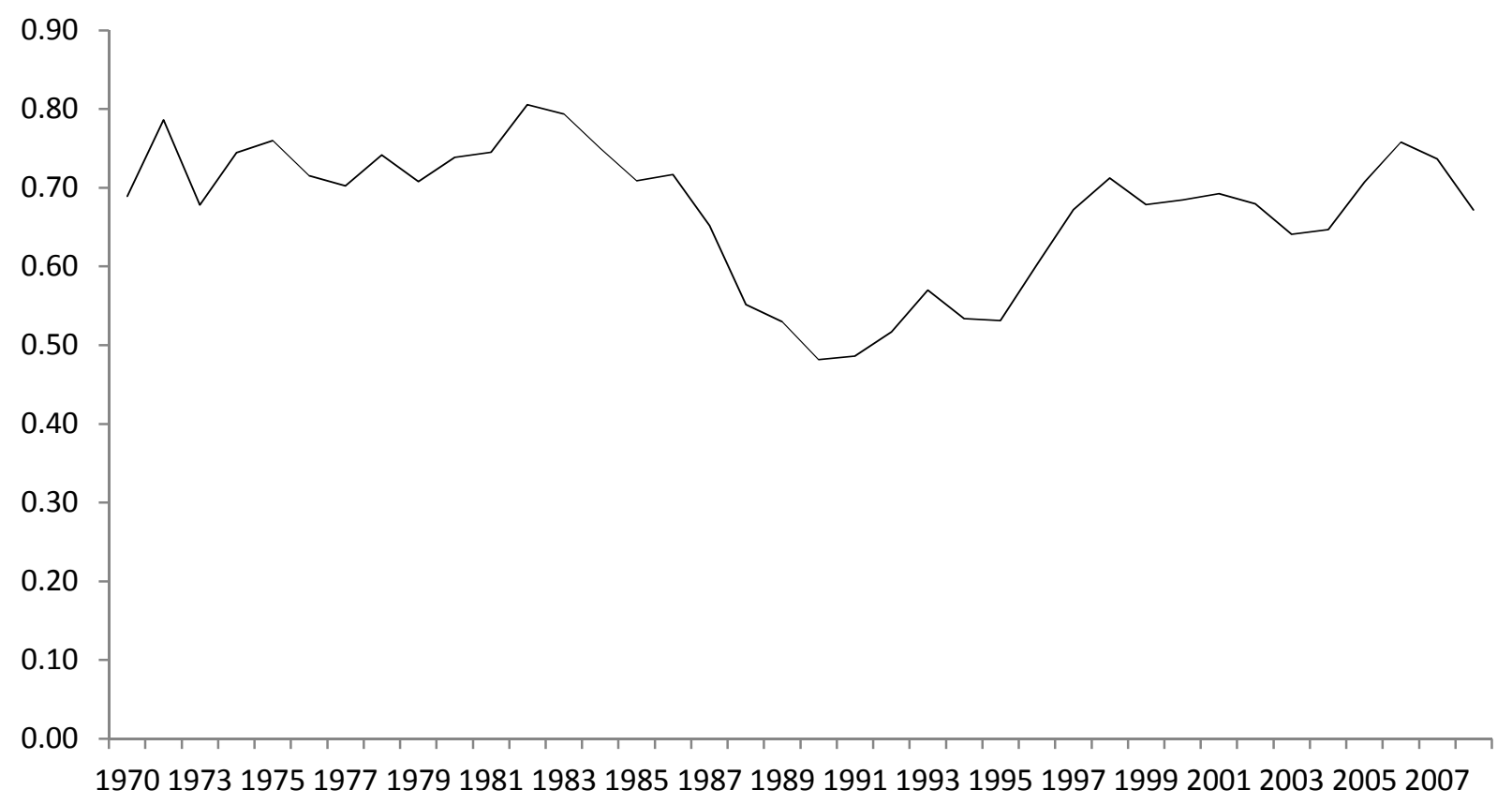

Figure 5: Net Capacity Utilization Rate (1970-71 to 2007-08) in Indian Manufacturing Source: Author's own Calculations 


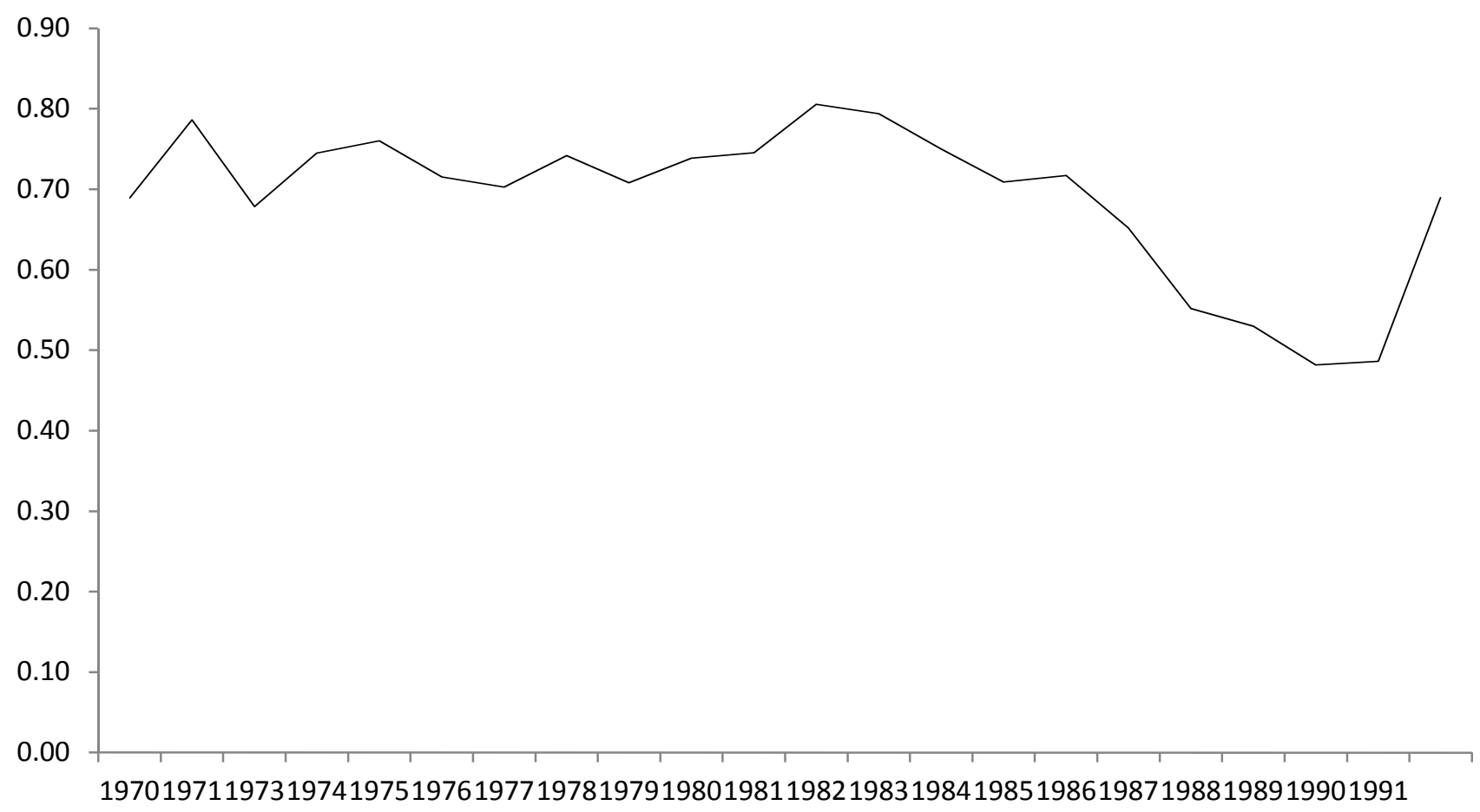

Figure 6: Net Capacity Utilization Rate (Pre-Reform) in Indian Manufacturing Source: Author's own Calculations 


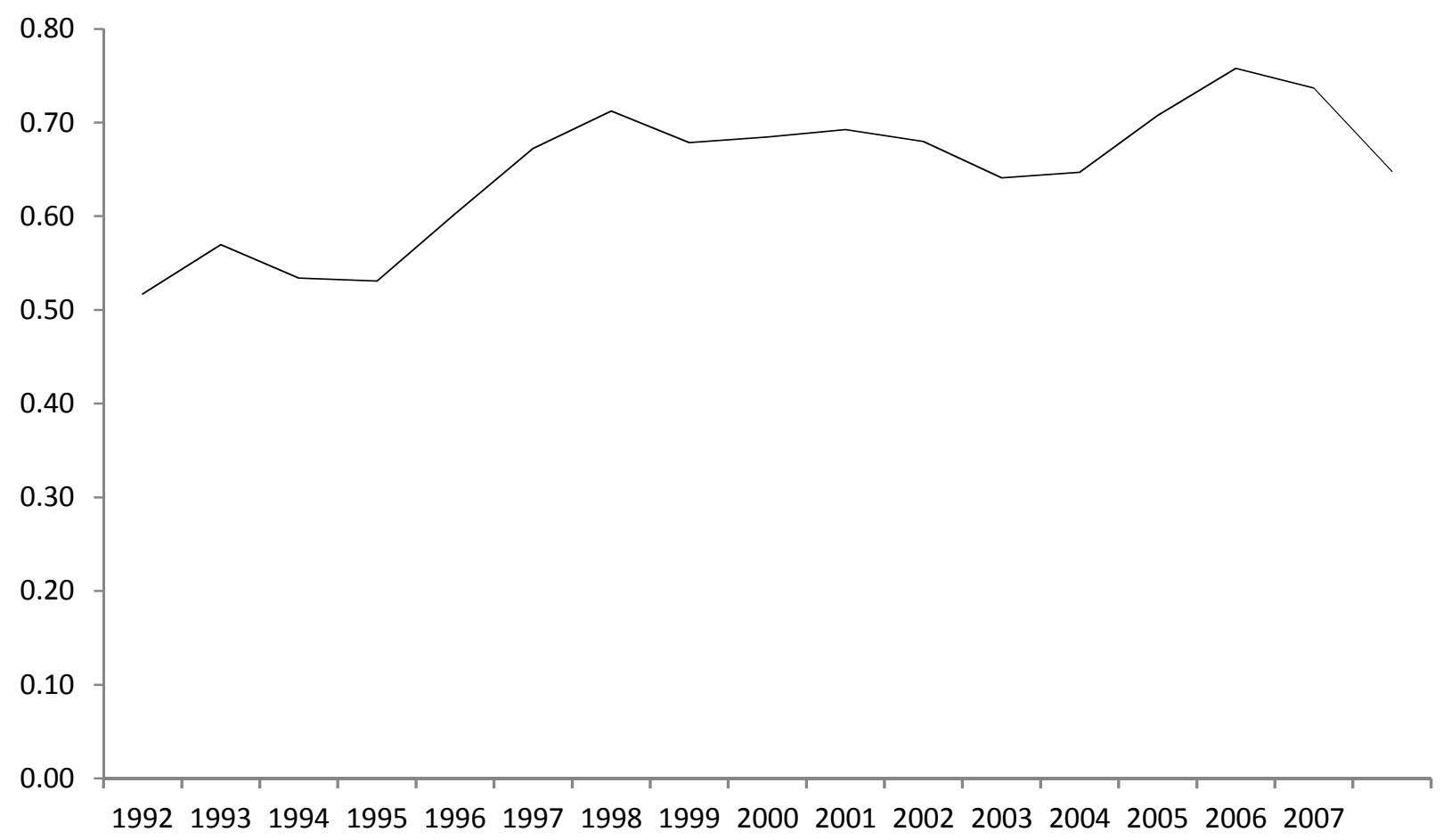

Figure 7: Net Capacity Utilization Rate (Post-Reform) in Indian Manufacturing Source: Author's own Calculations 


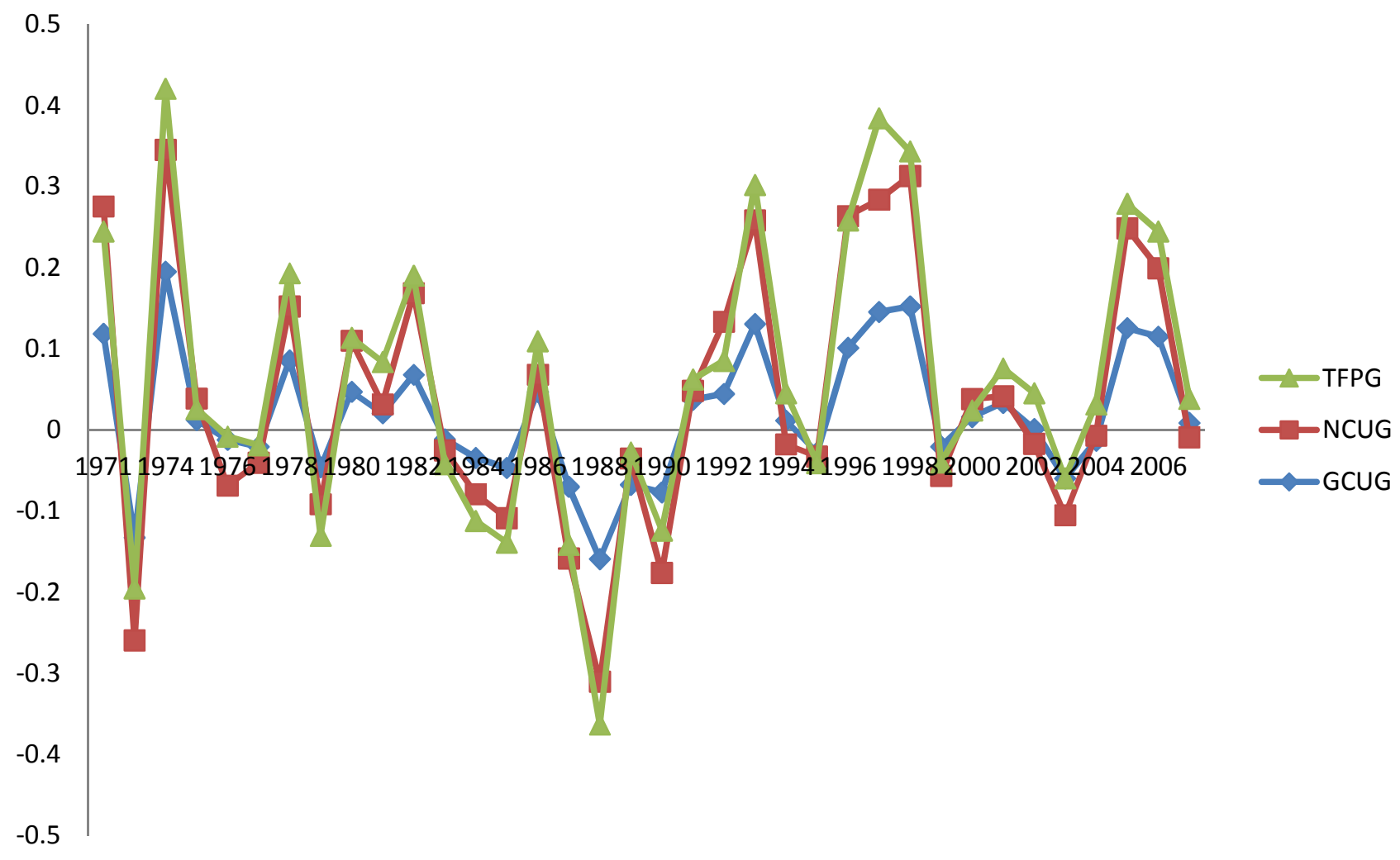

Figure 8: Total Factor Productivity and Capacity Utilization Growth Rate in Indian Manufacturing

Source: Author's own Calculations and Deb and Ray, 2013 
Appendix: Acronyms used for Indian States

1. AP (Andhra Pradesh)

2. AS (Assam)

3. BI (Bihar)

4. $\quad \mathrm{CH}$ (Chandigarh)

5. DE (Delhi)

6. $\mathrm{GO}$ (Goa)

7. GU (Gujarat)

8. HA (Haryana)

9. HP (Himachal Pradesh)

10. KA (Karnataka)

11. KE (Kerala)

12. MH (Maharashtra)

13. MP (Madhya Pradesh)

14. OR (Orissa)

15. PO (Pondicheri)

16. PU (Punjab)

17. RA (Rajasthan)

18. TN (Tamil Nadu)

19. UP (Uttar Pradesh)

20. WB (West Bengal) 